\title{
University of Alberta norms of relative meaning frequency for 566 homographs
}

\author{
LESLIE C. TWILLEY, PETER DIXON, DEAN TAYLOR, and KAREN CLARK \\ University of Alberta, Edmonton, Alberta, Canada
}

\begin{abstract}
For many models of lexical ambiguity resolution, relative frequency of the different meanings of homographs (words with more than one meaning) is crucial. Although several homograph association norms have been published in the past, none has involved a large number of subjects responding to a large number of homographs, and most homograph norming studies are now at least a decade old. In Experiment 1, associations to 566 homographs were collected from an average of 192 subjects per homograph. Frequency of occurrence for the three most common meanings is reported, along with the corresponding associates, and a measure of the overall ambiguity of each homograph. Homographs whose meanings differed in part of speech were more ambiguous overall than homographs whose different meanings belonged to a single grammatical class. Homographs whose pronunciation depended on meaning (heterophones) were no more ambiguous than nonheterophones, and word frequency was unrelated to overall ambiguity. Estimates of homograph balance across different norming studies were compared, and homographs with two meanings of approximately equal relative meaning frequency (balanced homographs) and homographs with one clearly dominant meaning (polarized homographs) were identified. In Experiment 2 , reliability of meaning categorizations was measured for a subset of the homographs in the first experiment. Meaning categorizations were shown to be highly reliable across raters.
\end{abstract}

Homographs are words that have more than one meaning but share the same orthography. They most often also share phonology (e.g., a dog's bark vs. a tree's bark; a fireplace poker vs. a poker game), but a few English homographs have distinct phonologies for their different meanings. For these heterophonic homographs, pronunciation depends on meaning; examples are "bass" (fish vs. guitar) and "wind" (gale vs. to coil). Contrary to intuition, homographs are not an obscure class of linguistic items. Rather, homographs could be considered important topics of study solely because of their abundance in English. Britton (1978) found that $44 \%$ of a random sample of English words had more than one meaning, and that $85 \%$ of a sample of high-frequency English words had more than one meaning. Several authors have argued that meaning indeterminacy in language and the environment in general is widespread and is one of the pervasive problems of human information processing (e.g., Simpson, 1989; Simpson \& Burgess, 1988; Swinney, 1991; Yates, 1985).

There are other, more empirically driven reasons why cognitive scientists might wish to understand homograph

\footnotetext{
This research was funded by a Natural Sciences and Engineering Council of Canada (NSERC) operating grant to P. Dixon. L. C. Twilley was supported by an NSERC postgraduate scholarship. The authors would like to thank D. Nelson, T. Neill, and an anonymous reviewer for many helpful comments and suggestions. Requests for reprints should be sent to L. Twilley or P. Dixon, Department of Psychology, University of Alberta, Edmonton, Alberta, T6G 2E9 (e-mail: twilley@psych.ualberta.ca).
}

-Accepted by previous editor, Margaret Jean Intons-Peterson processing. The resolution of lexical ambiguity, including its time course and interaction with context, has been a critical issue in the modularity debate in discussions of lexical access (Neill \& Klein, 1989; Prather \& Swinney, 1988; Simpson, 1984; Simpson \& Burgess, 1988; Swinney, 1991). A central question is whether the processes that access a word's meaning can be penetrated by the context in which the word appears. Homographs are a particularly attractive stimulus type to use because orthography and even phonology can be controlled, leaving only meaning to vary. This eradicates the influence of uncontrolled lexical variables that is possible with nonidentical target stimuli that are simply matched on characteristics such as word frequency, length, and number of syllables. Many researchers in this area have argued that the relative frequency of multiple meanings determines the course of lexical access (e.g., Carpenter \& Daneman, 1981; Hogaboam \& Perfetti, 1975; Neill, Hilliard, \& Cooper, 1988; Rayner \& Morris, 1991; Simpson, 1984; Simpson \& Burgess, 1985).

Unfortunately, existing frequency norms for homograph meanings are unsatisfactory for many purposes. That is, many of the published norms of homograph meaning frequency have included data for only a small number of homographs, and others used too few subjects to ensure adequate reliability. As Table 1 shows, three of the studies used 50 or fewer homographs (Geis \& Winograd, 1974; Kausler \& Kollasch, 1970; Warren, Bresnick, \& Green, 1972 ) and three used fewer than 100 subjects (Geis \& Winograd, 1974; Gilhooly \& Logie, 1980; Nelson, McEvoy, Walling, \& Wheeler, 1980). In fact, none of the pub- 
Table 1

\begin{tabular}{lccrrr}
\multicolumn{5}{c}{$\begin{array}{c}\text { Number of Homographs, Number of Responses per } \\
\text { Homograph, and Percent Overlap and } \boldsymbol{R} \text {-squared } \\
\text { With Our Data Set, for Nine Other Studies }\end{array}$} \\
\hline \multicolumn{1}{c}{ Study } & Homographs & $\begin{array}{c}\text { Responses per } \\
\text { Homograph }\end{array}$ & \% Overlap & $\boldsymbol{R}^{\mathbf{2}}$ \\
\hline Cramer (1970) & 100 & 109 & 99 & .66 \\
Kausler \& Kollasch (1970) & 40 & 200 & 100 & .74 \\
Perfetti et al. (1971) & 109 & 108 & 92 & .77 \\
Warren et al. (1972) & 20 & 100 & 75 & .52 \\
Geis \& Winograd (1974) & 50 & 68 & 100 & .79 \\
Gilhooly \& Logie (1980) & 387 & 40 & 34 & .53 \\
Nelson et al. (1980) & 317 & 46 & 100 & .85 \\
Wollen et al. (1980) & 120 & 108 & 99 & .61 \\
Gorfein et al. (1982) & 96 & 100 & 86 & .88 \\
\hline
\end{tabular}

lished norms used both a large number of homographs and a large number of subjects. Cramer (1970), Gorfein, Viviani, and Leddo (1982), Perfetti, Lindsey, and Garson (1971), and Wollen, Cox, Coahran, Shea, and Kirby (1980) each used moderate numbers of both homographs and subjects. We think that our data will be invaluable to researchers who require quantification of homograph meaning frequencies that is both reliable and comprehensive; we report data for 566 homographs, each homograph having been responded to by an average of 192 subjects. It is also important to ensure the recency of any linguistic norms because linguistic usage may change in a relatively short period of time. This is the first published large-scale homograph meaning frequency norming study in the last decade. Furthermore, the size of our corpus of homographs permits investigation of an issue which has received little attention to date: reliability of estimates of homograph balance (balanced homographs have two relatively equally frequent meanings; polarized homographs have a primary meaning which is much more frequent than the next most common meaning). The continuum of homograph balance is theoretically meaningful, and is a design issue in some lexical ambiguity experiments (e.g., Duffy, Morris, \& Rayner, 1988; Rayner \& Frazier, 1989). Observed differences in processing between items varying in degree of balance are used to support arguments about how the language-processing system handles meaning indeterminacy. Several important studies have made critical theoretical arguments based on homograph balance effects. Until now, however, there have been little data addressing the issue of how variable such estimates are from one norming situation to another.

Two studies provide evidence that homograph-meaning frequencies are generally quite stable, and that homographs whose primary meaning has a high relative frequency are more stable than homographs with less frequent primary meanings. Gorfein et al. (1982) had subjects produce four associations for each of a list of homographs. Eighty-two percent of the subjects produced associations to the same meaning on the first and second associations; $66 \%$ produced associations to the same meaning all four times. The correlation between proba- bility of producing the same meaning across four associations and primary meaning strength was .84 . Geis and Winograd (1974) calculated test-retest reliabilities for single word associations to homographs. Associations to the same meaning on both trials occurred $83 \%$ of the time. The correlation between probability of responding with the same meaning on both trials and strength of primary meaning was .70 to .76 (after delays of $5 \mathrm{~min}$ and $48 \mathrm{~h}$, respectively). The results of these two studies are less than conclusive, however, given the methodology used. Requiring multiple associations seems especially prone to strategic factors, lessening the value of such results as indicators of lexical variables. We address the issue of reliability by comparing relative meaning frequencies and balance estimates across 10 sets of independently collected norms from various regions.

We used single word associations to obtain meaning information for our set of homographs. Word association has been the method of choice for obtaining estimates of relative meaning frequencies in the lexicon (e.g., Cramer, 1970; Geis \& Winograd, 1974; Gilhooly \& Logie, 1980; Gorfein et al., 1982; Kausler \& Kollasch, 1970; Nelson et al., 1980; Perfetti et al., 1971). It is assumed that associates to lexical items are produced in proportion to the strength of the related semantic features of the items-in the case of homographs, in proportion to the strength of the different meanings. This assumption is supported by findings showing that words related to semantic features of other words can be used as primes for those words, and that the amount of priming is related to the centrality of the feature, for both homographs (e.g., Kellas, Paul, Martin, \& Simpson, 1991; Tabossi, Colombo, \& Job, 1987) and nonhomographs (e.g., Barclay, Bransford, Franks, McCarrell, \& Nitsch, 1974; Barsalou, 1982). Kausler and Kollasch (1970) found that the semantic word counts of Lorge and Thorndike (1938, cited in Kausler \& Kollasch, 1970) predicted the dominant meanings of homographs in their word-association norming study approximately $75 \%$ of the time. Single word associations thus appear to be a valid method of obtaining estimates of actual meaning frequencies occurring in the linguistic environments of readers or speakers. 


\section{EXPERIMENT 1}

\begin{abstract}
Method
Subjects. The subjects were 458 undergraduates participating for course credit in a single large introductory psychology class at the University of Alberta in September 1991; the experiment was run during a regular class period. Seventy-four subjects reported a first language other than English; their data were not included in the analyses, leaving a total of 384 subjects.
\end{abstract}

Materials. Stimuli were culled from a number of sources. Most stimuli in the norms of Cramer (1970), Geis and Winograd (1974), Kausler and Kollasch (1970), Nelson et al. (1980), and Wollen et al. (1980) were included (excluded stimuli were different forms of homographs already in the sample; a few stimuli were also inadvertantly omitted). Also included were homographs we generated for experiments on activation and suppression of homograph meanings (Twilley \& Dixon, 1992). Substantial overlap resulted with other norming sets that came to our attention after creation of the homograph list. Overlap between our list of homographs and those in the other norming studies is expressed in Table 1 as the percentage of homographs from the other norms that were included in our sample. In our sample of homographs, $75.6 \%$ had at least one meaning for which the subjects' responses could be classified into more than one grammatical class (e.g., a sand desert vs. to desert someone, to bowl vs. to fill a bowl); such homographs fall under the heading of "syntactic category ambiguity" (Rayner \& Morris, 1991). Heterophonic homographs comprised $5.7 \%$ of the sample. For our purposes, homographs were considered heterophonic if pronunciation depended on meaning, including a change in the pronunciation of one or more phonemes (e.g., $/ \mathrm{bas} / \mathrm{vs}$. /bes/) and/or a change in stress pattern (e.g., /in' sens/vs. /in sens'/) with meaning. Mean Kučera and Francis (1967) word frequency for the stimuli was 83.6 per million (median $=26.5, S E=7.5$ ).

There was insufficient time in the experimental session for subjects to respond to all 566 homographs. Instead, each subject responded to half of the items. Half of the items were randomly chosen and ordered for one subject, and the other 283 items were randomly ordered for the next subject. This procedure was repeated until stimuli were generated for $\mathbf{5 0 0}$ subjects. This resulted in the randomization across subjects of both choice and order of items. On average, 192 responses to each item were included in the analyses ( 384 subjects with English as a first language completed 283 responses each). Stimuli were presented on two sheets of paper of three columns each. Each homograph was followed by a blank line for the subject's response.

Procedure. The subjects were provided with written instructions, which were explained by one of the experimenters. They were asked to write down the first word they thought of as they read each homograph. They were told that any response was appropriate, as long as it was the first word that came to mind when they saw the stimulus word. Stimuli were to be completed in order (down the columns), and the subjects were asked not to go back and change any responses. The written instructions sheet covered the two stimulus sheets, so that the subjects had no advance viewing of the stimuli. No mention was made of the homographic nature of the items. Several experimenters walked around the room during instructions and completion of the task to ensure that the task was being carried out as directed. The task took $20-30 \mathrm{~min}$ to complete.

Scoring. Two raters scored the responses collaboratively. One category was created for each distinct meaning of the homograph that was used by the subjects; there was also an "Unclear" category. Unclear responses were of three types. Any response that was itself ambiguous, in that it could fit with more than one of the meanings for the homograph, was put into the Unclear category (i.e., "hand" in response to "second" could mean the second hand of a watch or it could mean a second-hand item). Responses that had no apparent association with the homograph were also categorized as Unclear. Finally, some Unclear responses involved an in- correct association (such as responding "strawberries" to "desert," or "chicken" to "foul"). After the two raters had scored the responses, a third rater reviewed all of their decisions; any errors or nonobvious decisions were discussed with one of the two original raters, and changes were made if necessary.

Number of distinct meanings produced varied from 1 (for 28 of the stimuli) to 7 (for "set"), with a mean of $2.53(S E=.037)$. Meanings were judged to be separate if they could be reliably distinguished from each other on the basis of one or more semantic features. Distinctiveness of meanings was easier to judge for some homographs than for others. Such words as "quack" or "cricket," for example, have meanings with virtually no semantic overlap; they were relatively easy to categorize. Such words as "advance" and "order," which have several meanings that are somewhat similar, were more difficult to categorize reliably. For some words (e.g., "light" or "dress"), closely related meanings were collapsed into a single category because subjects' responses were not separable with one consistent feature; rather, responses were compatible with different shades of a single meaning. Raters had the overall goal of distinguishing categories as consistently as possible while avoiding excessive assignment of responses to the Unclear category.

Following Britton (1978) and Perfetti et al. (1971), an informationtheory measure of uncertainty (Attneave, 1959) was calculated for each homograph. This was calculated using the formula $U=$ $\sum_{i=1}^{n} p_{i} \log _{2}\left(1 / p_{i}\right)$, where $n$ is the number of distinct meanings for that homograph and $p_{i}$ is the proportion of responses associated with meaning $i$. The Unclear category was excluded in calculating these proportions. $U$ can be thought of as a measure of the overall ambiguity of a homograph: the larger the value of $U$, the more ambiguous the homograph. A two-meaning homograph whose responses all fell into one meaning would have a $U$ value of 0 ; a two-meaning homograph with equiprobable meanings would have a $U$ value of 1. The maximum value of $U$, and thus the possible range for $U$, increases with number of meanings.

To enable comparisons of balance estimates for homographs across different norming studies, we calculated a balance estimate, $B$, for each homograph. $B$ was calculated with the same formula as $U$, but only the two most frequent meanings were included (their relative frequencies were normalized to sum to 1 ). The resulting metric had a range from 0 to 1 and represented the degree to which the most common meaning was dominant over the secondary meaning. A homograph with a $B$ value of 1 had a secondary meaning with a relative frequency equal to that of the primary meaning; a $B$ value of 0 indicated that the secondary meaning had a relative frequency of 0 . This measure quantified the often discussed relationship between the primary and secondary meanings of a homograph (see, e.g., Duffy et al., 1988; Rayner \& Frazier, 1989). B values were also calculated for the homographs in our corpus from the relative frequencies provided in the other nine norming studies; the two meanings used were the primary and secondary meanings in our norms. Table 2 contains the $R^{2}$ values between our norms and the other norms for the balance measure.

\section{Results}

Appendix A contains the condensed data for the norms. ${ }^{1}$ For the three most common meanings (or fewer, if there were fewer than three meanings given as responses), the primary associate for that meaning is reported, followed by the relative frequency of that associate, followed by the relative frequency of that meaning category. The last three columns of Appendix A represent the relative frequency of other meanings, the relative frequency of Unclear categorizations, and $U$. Relative frequencies are expressed as the proportion of all responses to that homograph. Table 3 shows means and standard errors of the 
Table 2

$R^{2} \mathbf{s}$ for Balance Estimates

\begin{tabular}{|c|c|c|c|c|}
\hline \multirow[b]{2}{*}{ Study } & \multicolumn{2}{|c|}{ Entire Data Set } & \multicolumn{2}{|c|}{$\begin{array}{l}\text { Balanced/Polarized } \\
\text { Homographs Only }\end{array}$} \\
\hline & $R^{2}$ & Count & $R^{2}$ & Count \\
\hline Cramer (1970) & .04 & 98 & 0 & 28 \\
\hline Kausler \& Kollasch (1970) & $.26 *$ & 37 & .16 & 11 \\
\hline Perfetti et al. (1971) & $.27^{*}$ & 98 & $.29 *$ & 27 \\
\hline Warren et al. (1972) & .18 & 15 & .84 & 3 \\
\hline Geis \& Winograd (1974) & $.38 *$ & 50 & $.67 *$ & 13 \\
\hline Gilhooly \& Logie (1980) & $.09 *$ & 133 & $.24^{*}$ & 40 \\
\hline Nelson et al. (1980) & $.48^{*}$ & 316 & $.56^{*}$ & 100 \\
\hline Wollen et al. (1980) & $.34 *$ & 119 & $.46 *$ & 35 \\
\hline Gorfein et al. (1982) & $.63^{*}$ & 83 & $.75^{*}$ & 22 \\
\hline
\end{tabular}

$* p<.05$.

various relative frequencies and $U$, as well as number of homographs associated with each relative frequency (means for second, third, and other meanings were based on less than 566 homographs, because not all homographs had frequencies greater than zero for second and higher meanings).

To determine whether grammatical class variation, heterophony, and word frequency were related to $U, t$ tests were carried out. $U$ values were higher for homographs with at least one meaning for which subjects' responses could be classified into more than one grammatical class $(M=.76, S E=.02)$ than they were for homographs for which meanings were all within a single grammatical class $(M=.60, S E=.04)[t(564)=3.35, p<.001]$. Heterophones $(M=.83, S E=.09)$ did not differ from nonheterophones $(M=.71, S E=.02)[t(564)=1.35, p>$ .10]. The correlation between $U$ and word frequency was minimal $(R=.05, p>.10)$.

Correlations between meaning frequencies in our norms and those of other norms are shown in the last column of Table 1 (note that in 7 of the 956 cases in which a homograph in our stimulus set appeared in another study, the meaning categorizations used by the other study were incompatible with ours. These 7 cases were not included in the across-study correlations). The $R^{2}$ values are all quite high, ranging from .52 to .88 (all $p \mathrm{~s}<.05$ ). The correlations with the Wollen et al. (1980) and Warren

Table 3

Means, Standard Errors, and $N$ for the Various Frequencies and $U$

\begin{tabular}{llll}
\hline \multicolumn{1}{c}{ Variable } & $M$ & $S E$ & $N$ \\
\hline P1 & .25 & .006 & 566 \\
M1 & .71 & .007 & 566 \\
P2 & .07 & .003 & 538 \\
M2 & .16 & .005 & 538 \\
P3 & .03 & .002 & 230 \\
M3 & .07 & .004 & 230 \\
Remaining Meanings & .05 & .006 & 75 \\
Unclear category & .10 & .003 & 566 \\
$U$ & .72 & .020 & 566 \\
\hline
\end{tabular}

Note-P1, P2, P3 = proportion of primary associate responses to the homograph for the first, second, and third most frequent meanings, respectively. M1, M2, M3 = proportion of responses to the homograph for the first, second, and third most frequent meanings, respectively. $U=$ overall ambiguity of the homograph in terms of uncertainty of information. et al. (1972) norms are among the lowest (.61 and .52 , respectively). These are the only two studies that did not use the word-association measure. This provides support for the claim that word association and sentence generation or definition writing are tapping somewhat different processes, perhaps due to the increased opportunity for strategic responding in tasks like sentence generation and definition writing. Gilhooly and Logie (1980) did not include meanings given by $10 \%$ or less of their subjects; such a procedure applied to our data would exclude a substantial number of meanings. This restriction of their sample may explain the low correlation (.53) with our data. Similarly, Cramer (1970) arbitrarily restricted her meaning categories to two for all homographs; third or higher meanings were disregarded. This discrepancy in number of meaning categories between her study and ours would decrease the correlation (which was .66). The $R^{2}$ values for the remaining five sets of norms range from .74 to .88 , leaving $12 \%$ to $26 \%$ of the variance unexplained. Some of this variability may be due to regional differences, differences in year (or decade) of testing, and discrepancies in meaning definition (i.e., some studies combined meanings that were considered distinct in others). However, the $R^{2}$ values are sufficiently high to allow use of our norms in situations other than the one in which they were collected.

Many informative experimental designs involve comparing polarized and balanced homographs; it is thus of interest to look at the reliability of balance estimates for the two extremes of the balance distribution. Two groups of homographs were identified, including 86 balanced homographs with $B$ values of .95 and higher and 96 polarized homographs with $B$ values of .1 to .3 (homographs with $B$ values between 0 and .1 were rejected in order to exclude homographs with a very rare secondary meaning which might not be known to all readers). $R^{2}$ values for these stimuli are given in Table 3. Appendix B lists the homographs in the polarized and balanced sets.

\section{Discussion}

It is noteworthy that many of the homographs in our list have more than two meanings; nearly half (230) have three or more meanings, and 75 have four or more meanings. In some previous studies, possible responses and/or 
categorizations of responses were limited to just two meanings. Our results show that such a strategy will underestimate the ambiguity of many homographs. Number of meanings has theoretical importance to models such as the ordered-access model (Hogaboam \& Perfetti, 1975) or the activation-suppression model of Neill and colleagues (e.g., Neill, 1989; Neill et al., 1988). In these models, the time taken to search for all meanings of a homograph is limited by search time for the least frequent meaning (although this can be overridden by context in Neill's model). Accurate modeling of search time by these models would require knowledge of frequencies of all meanings of homographic stimuli. Using frequency estimates from norms in which number of meanings is limited to two would underestimate search times for those cases in which third most frequent (or rarer) homograph meanings are used.

$U$ has not been widely used as an index of overall ambiguity for homographs, so we do not have an established base of data with which to compare our findings. Neither Perfetti et al. (1971) nor Britton (1978) reported correlations between $U$ and any other lexical characteristics, and theirs are the only studies we are aware of in which the uncertainty-of-information measure is applied to homographs. The finding of significantly higher $U$ values for homographs with grammatical class variability indicates that semantic flexibility covaries with syntactic flexibility. Some researchers have studied noun-verb homographs separately from noun-noun homographs (e.g., Frazier \& Rayner, 1987; Seidenberg, Tanenhaus, Leiman, $\&$ Bienkowski, 1982). Seidenberg et al. found that processing of syntactic-category ambiguity differs from that of within-syntactic-category ambiguity. They found that semantic priming of noun-noun homographs (e.g., organ) led to selective access of the appropriate meaning of the homographs, but that semantic priming of noun-verb homographs (e.g., tire) failed to produce selective access. Our findings point to a potential confound in this work: The difference in processing found may be related to the fact that syntactic-category ambiguity covaries with overall semantic uncertainty $(U)$. This allows the possibility that it was not syntactic-category ambiguity but simply high overall ambiguity that led to exhaustive access for the noun-verb homographs.

There was no difference in $U$ between heterophones and nonheterophones in our sample. The data show a trend toward greater overall ambiguity for heterophones, but this trend is unreliable, perhaps partially due to the small number (32) of heterophones in our sample (indeed, in the English language). Gorfein et al. (1982) report that heterophones show greater meaning stability (across repeated associations) than do nonheterophones, but they do not report $U$ for their homographs. Warren et al. (1972), whose stimuli were all heterophones, found a mean of 2.4 meanings per heterophone, which is very similar to the mean of 2.53 meanings for our sample and is not different from the mean of 2.56 for nonheterophones in our sample. Thus, the data are mixed with regard to whether heterophones might be expected to behave differently from nonheterophones in experimental tasks.

We found no relationship between word frequency and $U$. The data on similar relationships in other stimulus sets are limited. Britton (1978) reports high semantic uncertainty for high-frequency words, although his data are based on dictionary entries rather than actual usage. Cramer (1970) found no relationship between word frequency and frequency of the most common meaning (nor do we; $F=1.88, p>.05$ ). She does report that the difference between first and second meaning frequencies increases with decreasing frequency, although this observation is not supported by statistical analysis. Similar analyses on our data indicate no such relationship $(F=$ $1.25, p>.05)$. Ferraro and Kellas (1990) had subjects rate homographs as having 0,1 , or 2 meanings. The correlation between these ratings and word frequency was significant, but small $[r(388)=.18]$. Paivio, Yuille, and Madigan (1968) report that high-frequency words are more meaningful, in that more associative responses are generated for them within a limited time period; this measure is clearly not the same as $U$ or number of meanings, however. Thus, the relationship between various measures of ambiguity and word frequency is inconsistent across other data sets, and is not evident in our data either. It is likely that a relationship, if it exists, is small.

We provided data on the stability of balance estimates across norms. The $R^{2}$ values indicate that balance estimates are generally stable across norming studies, and that extreme-groups designs like those used in many studies produce a stable balance contrast.

\section{EXPERIMENT 2}

It is important to have an index of the reliability of the meaning classifications used in these norms. One such index is the interrater reliability for assignment to meaning categories. These data are not available for the entire data set for two reasons. First, we felt that collaboration rather than some sort of statistical resolution of disagreements between raters produced a more valid and more stable set of classifications. In many cases in Experiment 1, one rater was able to provide information unknown or unconsidered by the other rater which caused that rater to change his or her categorization. Second, separate categorizations and subsequent combination of these categorizations was simply not feasible for the 33,078 distinct responses. In Experiment 2, interrater reliabilities were calculated for a subset of the homographs in order to provide an estimate of the reliability of the original classifications.

\section{Method}

Materials. Fifty-eight homographs (10.2\% of the original corpus) were chosen, half of which were moderately polarized (mean $B$ value $=.852, S E=.009$ ) and half of which were balanced according to the original raters' categorizations (mean $B$ value $=.997$, $S E=.001$ ). Because of the constraints of the optical scanning sheets used for computer scoring of categorizations, homographs with more than nine dictionary meanings were excluded. 
Raters. Four raters were employed to independently score the responses to these homographs. None had been involved in scoring the original responses, and all reported English as a first language.

Scoring. Meaning categories were the dictionary definitions of the homographs in a pocket dictionary (Drysdale, 1991). Dictionary definitions were provided to ensure that all judges used the same categories, thus enabling interrater comparisons. These comparisons served as an estimate of the reliability of classifications of word associations into meaning categories. Furthermore, the use of dictionary definitions gave us a method of gauging the appropriateness of our original judges' decisions about collapsing across related meanings due to featural overlap. Any increase in interrater reliability observed after dictionary definitions were collapsed to match the categories generated by our original judges is due to the suitability of the decisions to combine related meanings. A decrease in reliability would indicate that the meaning categories were not collapsed in a manner consistent with the four new raters' judgments. The correlations between the original raters and the new raters also provide an estimate of the lower bound on the reliability of the original raters' categorizations.

When a response was deemed appropriate for more than one definition, raters were told to choose the most appropriate definition. This ensured that responses were deemed "Unclear" only when they were simply unrelated to the homograph or were erroneous responses. Because closely related meanings were to be collapsed after calculating original interrater reliabilities, this procedure maximized the data available with which to estimate interrater reliability.

\section{Results and Discussion}

Interrater reliabilities were calculated for all six possible pairings of the 4 raters. The dependent measure was percent overlap in assignment to dictionary definition categories, corrected for chance. The formula used was (\% overlap - chance level)/(1 - chance level), with chance level equal to ( 1 /number of dictionary definitions). The resulting means are given in Table 4 . Means for percent overlap after collapsing meaning categories, corrected for chance, can be found in Table 5 .

Mean overlap between raters was $64 \%$ before collapsing across dictionary definitions and $76 \%$ after collapsing ( $70 \%$ and $83 \%$, respectively, before chance correction); this $12 \%$ difference was significant $[F(1,56)=51.6, p<$ .05]. There was no main effect of balance $[F(1,56)=$ $1.4, p>.05]$; nor did meaning source and balance interact $[F(1,56)<1, p>.05]$. Thus, after correcting for chance, overlap was substantial and improved significantly when the original raters' categorizations were used to collapse dictionary definitions into categories consistent with those used in the norming study proper.

Mean overlap between the 4 raters and the original ratings was $76 \%$ ( $82 \%$ before chance correction); this was

Table 4

Percent Overlap in Meaning Categorizations for Four Raters (Corrected for Chance)

\begin{tabular}{ccccc}
\hline & \multicolumn{4}{c}{ Rater } \\
\cline { 2 - 5 } & 1 & 2 & 3 & 4 \\
\hline 1 & - & 66 & 65 & 62 \\
2 & & - & 62 & 60 \\
3 & & & - & 61 \\
\hline
\end{tabular}

Table 5

Percent Overlap in Meaning Categorizations for 4 Raters and Original Raters (Corrected for Chance), After Collapsing Meaning Categories

\begin{tabular}{cccccc}
\hline & \multicolumn{5}{c}{ Rate } \\
\cline { 2 - 6 } & Orig. & 1 & 2 & 3 & 4 \\
\hline Orig. & - & 75 & 74 & 77 & 76 \\
1 & & - & 75 & 77 & 75 \\
2 & & & - & 76 & 75 \\
3 & & & & - & 78 \\
\hline
\end{tabular}

Note-Orig. = Original raters.

identical to the mean interrater overlap for the 4 subset raters. There was a marginal main effect of balance $[F(1,56)=3.7, p<.10]$. Examination of the overlap distribution revealed three clear outliers. For one of the homographs ("chuck"), overlap between the 4 raters was high, but overlap with the original raters was low. This occurred because many of the responses to "chuck" referred to its use as a proper name; proper names did not appear in the dictionary definitions used by the four subset raters. For the other two homographs ("copy" and "hatch"), overlap was low between the 4 raters as well as between the 4 raters and the original raters. These homographs thus had meanings that were simply difficult to discriminate along a single semantic feature. When these three items were removed from the analysis, there was no effect of balance on reliability of meaning categorization $[F(1,53)<1, p>.05]$.

\section{CONCLUSIONS}

Homographs appear in the stimulus lists of countless experiments dealing with central issues in the study of semantic processing. Some of the key issues revolve around comparisons of meanings differing in relative frequency, and normative estimates of relative meaning frequencies are essential. We have provided data on a large number of homographs, and we have demonstrated that our meaning categorizations are reliable. Comparisons of meaning categorizations and balance estimates across norming studies indicate that these measures are generally stable, although variations due to region and time of data collection may occur. We demonstrated that variables such as grammatical class are related to the overall ambiguity of homographs; an interesting future direction for research is to determine the role such relationships play in the resolution of meaning indeterminacies.

\section{REFERENCES}

Atrneave, F. (1959). Applications of information theory to psychology. New York: Henry Holt.

Barclay, J. R., Bransford, J. D., Franks, J. J., McCarrell, N. S., \& NrTsCH, K. (1974). Comprehension and semantic flexibility. Journal of Verbal Learning \& Verbal Behavior, 13, 471-481.

Barsalou, L. W. (1982). Context-independent and context-dependent information in concepts. Memory \& Cognition, 10, 82-93.

BRITTON, B. K. (1978). Lexical ambiguity of words used in English text. Behavior Research Methods \& Instrumentation, 10, 1-7. 
Carpenter, P.A., \& Daneman, M. (1981). Lexical retrieval and error recovery in reading: A model based on eye fixations. Journal of Verbal Learning \& Verbal Behavior, 20, 137-160.

Cramer, P. (1970). A study of homographs. In L. Postman \& G. Keppel (Eds.), Norms of word association. New York: Academic Press.

DRYSDALE, P. (1991). Collins pocket reference English dictionary. Glasgow: Harper Collins.

Duffy, S. A., MorRIs, R. K., \& RAYNer, K. (1988). Lexical ambiguity and fixation times in reading. Joumal of Memory \& Language, 27, 429-446.

Ferraro, F, R., \& Kellas, G. (1990). Normative data for number of word meanings. Behavior Research Methods, Instruments, \& Computers, 22, 491-498.

Frazier, L., \& RAYNER, K. (1987). Resolution of syntactic category ambiguities: Eye movements in parsing lexically ambiguous sentences. Journal of Memory \& Language, 26, 505-526.

GeIs, M. F., \& WINOGRAD, E. (1974). Norms of semantic encoding variability for fifty homographs. Bulletin of the Psychonomic Society, 3, 429-431.

GilHOOLY, K. J., \& LOGIE, R. H. (1980). Meaning-dependent ratings of imagery, age of acquisition, familiarity, and concreteness for 387 ambiguous words. Behavior Research Methods \& Instrumentation, $12,428-450$

Gorfein, D. S., Viviani, J. M., \& Leddo, J. (1982). Norms as a tool for the study of homography. Memory \& Cognition, 10, 503-509.

Hogaboam, T. W., \& Perfetti, C. A. (1975). Lexical ambiguity and sentence comprehension. Journal of Verbal Learning \& Verbal Behavior, 14, 265-274.

Kausler, D. H., \& Kollasch, S. F. (1970). Word associations to homographs. Journal of Verbal Learning \& Verbal Behavior, 9, 444-449.

Kellas, G., Paul, S. T., Martin, M., \& Simpson, G. (1991). Contextual feature activation and meaning access. In G. B. Simpson (Ed.), Understanding word and sentence (pp. 47-71). Amsterdam: Elsevier.

Kučera, H., \& FrancIs, W. N. (1967). Computational analysis of present-day American English. Providence, RI: Brown University Press.

NerlL, W. T. (1989). Lexical ambiguity and context: An activationsuppression model. In D. S. Gorfein (Ed.), Resolving semantic ambiguity (pp. 63-83). New York: Springer-Verlag.

Neill, W. T., Hilliard, D. V., \& CoOper, E. (1988). The detection of lexical ambiguity: Evidence for context-sensitive parallel access. Journal of Memory \& Language, 27, 279-287.

NeILL, W. T., \& KLEIN, R. M. (1989). Reflexions on modularity and connectionism. In D. S. Gorfein (Ed.), Resolving semantic ambiguity (pp. 276-293). New York: Springer-Verlag.

Nelson, D. L., MCEvoy, C. L., WAlling, J. R., \& WheEler, J. W. (1980). The University of South Florida homograph norms. Behavior Research Methods \& Instrumentation, 12, 16-37.

Paivio, A., Yuille, J. C., \& Madigan, S. A. (1968). Concreteness, imagery, and meaningfulness values for 925 nouns. Journal of $E x-$ perimental Psychology Monographs, 76(1, Pt. 2), 1-25.

Perfetti, C. A., Lindsey, R., \& Garson, B. (1971). Association and uncertainty: Norms of association to ambiguous words. Pittsburgh: Learning Research and Development Center, Unversity of Pittsburgh.
Prather, P. A., \& Swinney, D. A. (1988). Lexical processing and ambiguity resolution: An autonomous process in an interactive box. In S. I. Small, G. W. Cottrell, \& M. K. Tanenhaus (Eds.), Lexical ambiguity resolution (pp. 289-310). San Mateo, CA: Morgan Kaufmann.

RAYNER, K., Frazier, L. (1989). Selection mechanisms in reading lexically ambiguous words. Journal of Experimental Psychology: Learning, Memory, \& Cognition, 15, 779-790.

RAYNER, K., \& MORRIS, R. K. (1991). Comprehension processes in reading ambiguous sentences: Reflections from eye movements. In G. B. Simpson (Ed.), Understanding word and sentence (pp. 175198). Amsterdam: Elsevier.

Seidenberg, M. S., Tanenhaus, J. K., Leiman, J. M., \& Bienkowski, M. (1982). Automatic access of the meanings of ambiguous words in context: Some limitations of knowledge-based processing. Cognitive Psychology, 14, 489-537.

SIMPSON, G. B. (1984). Lexical ambiguity and its role in models of word recognition. Psychological Bulletin, 96, 316-340.

Simpson, G. B. (1989). Varieties of ambiguity: What are we seeking? In D. S. Gorfein (Ed.), Resolving semantic ambiguity (pp. 13-21). New York: Springer-Verlag.

Simpson, G. B., \& BuRgess, C. (1985). Activation and selection processes in the recognition of ambiguous words. Journal of Experimental Psychology: Human Perception \& Performance, 11, 28-39.

Simpson, G. B., \& BURGEss, C. (1988). Implications of lexical ambiguity resolution for word recognition and comprehension. In S. I. Small, G. W. Cottrell, \& M. K. Tanenhaus (Eds.), Lexical ambiguity resolution (pp. 271-288). San Mateo, CA: Morgan Kaufmann.

SwINNEY, D. A. (1991). The resolution of indeterminacy during language comprehension: Perspectives on modularity in lexical, structural, and pragmatic processing. In G. B. Simpson (Ed.), Understanding word and sentence (pp. 367-385). Amsterdam: Elsevier.

TAвossi, P., Colombo, L., \& Joв, R. (1987). Accessing lexical ambiguity: Effects of context and dominance. Psychological Research, 49 , 161-167.

Twilley, L. C., \& Dixon, P. (1992). Enhancement and suppression of homograph meanings. Unpublished manuscript.

Warren, R. E., Bresnick, J. H., \& Green, J. P. (1972). Definitional dominance distributions for 20 English homographs. Bulletin of the Psychonomic Society, 10, 229-231.

Wollen, K. A., Cox, S. D., Coahran, M. M., Shea, D. S., \& Kirby, R. F. (1980). Frequency of occurrence and concreteness ratings of homograph meanings. Behavior Research Methods \& Instrumentation, 12, 8-15.

YATES, J. (1985). The content of awareness is a model of the world. Psychological Review, 92, 249-284.

\section{NOTE}

1. A document containing all individual responses and their categorizations can be obtained from the authors. A disk copy will be sent in lieu of a paper copy if a 3.5 -in. disk is enclosed with the request (please indicate whether Macintosh or DOS format is required). FTP requests can also be accommodated.

APPENDIX A

Homograph Association Norms

\begin{tabular}{|c|c|c|c|c|c|c|c|c|c|c|c|c|}
\hline Homograph & Primary 1 & P1 & M1 & Primary 2 & P2 & M2 & Primary 3 & P3 & M3 & $R$ & $X$ & $U$ \\
\hline ACE & cards & .27 & .66 & pilot & .04 & .08 & tennis & .03 & .05 & .01 & .20 & .92 \\
\hline ACT & play & .23 & .74 & now & .03 & .11 & amendment & .01 & .02 & & .14 & .68 \\
\hline ADMIT & confess & .08 & .58 & one & .07 & .27 & & & & & .15 & .90 \\
\hline ADVANCE & forward & .12 & .49 & money & .09 & .26 & & & & & .24 & .93 \\
\hline AFFAIR & sex & .16 & .71 & current & .03 & .10 & & & & & .19 & .53 \\
\hline AIR & plane & .12 & .92 & grievances & .01 & .01 & & & & & .07 & .05 \\
\hline ANGLE & math & .19 & .81 & fish & .03 & .04 & approach & .01 & .01 & & .14 & .37 \\
\hline ANNUAL & yearly & .22 & .88 & book & .02 & .05 & & & & & .08 & .29 \\
\hline ARM & leg & .46 & .91 & gun & .03 & .05 & & & & & .04 & .31 \\
\hline ARTICLE & paper & .18 & .58 & clothing & .19 & .24 & lawyer & .03 & .06 & & .11 & 1.19 \\
\hline BALL & bat & .13 & .92 & dance & .02 & .02 & & & & & .07 & .13 \\
\hline
\end{tabular}


Homograph Association Norms (Continued)

\begin{tabular}{|c|c|c|c|c|c|c|c|c|c|c|c|c|}
\hline Homograph & Primary 1 & P1 & MI & Primary 2 & $\mathbf{P} 2$ & M2 & Primary 3 & P3 & M3 & $R$ & $X$ & $\underline{U}$ \\
\hline BAND & music & .31 & .63 & aid & .14 & .23 & $121.5-\mathrm{mz}$ & .01 & .01 & & .13 & .92 \\
\hline BANK & money & .54 & .98 & & & & & & & & .02 & .00 \\
\hline BAR & drink & .29 & .79 & soap & .03 & .07 & & & & & .14 & .39 \\
\hline BARK & $\operatorname{dog}$ & .61 & .68 & tree & .26 & .26 & & & & & .05 & .85 \\
\hline BASE & ball & .32 & .53 & bottom & .07 & .13 & army & .06 & .13 & .07 & .14 & 1.58 \\
\hline BASS & guitar & .13 & .56 & outlet & .09 & .19 & fish & .16 & .19 & & .06 & 1.37 \\
\hline BAT & ball & .39 & .53 & $\operatorname{man}$ & .07 & .34 & hit & .04 & .04 & & .09 & 1.19 \\
\hline BATTERY & car & .18 & .84 & assault & .04 & .06 & cannons & .01 & .01 & & .08 & .45 \\
\hline BAY & water & .16 & .45 & store & .13 & .21 & window & .07 & .08 & .05 & .21 & 1.61 \\
\hline BEAD & necklace & .47 & .85 & aim & .01 & .01 & & & & & .14 & .09 \\
\hline BEAM & light & .35 & .61 & wood & .04 & .23 & face & .01 & .02 & & .14 & .97 \\
\hline BEAR & grizzly & .08 & .82 & down & .01 & .01 & & & & & .17 & .05 \\
\hline BEEF & cow & .20 & .91 & & & & & & & & .09 & .00 \\
\hline BEING & human & .25 & .47 & here & .05 & .36 & & & & & .17 & .99 \\
\hline BELT & pants & .23 & .85 & hit & .07 & .07 & down & .01 & .01 & & .07 & .45 \\
\hline BEND & over & .18 & .57 & road & .05 & .16 & & & & & .26 & .76 \\
\hline BILL & money & .22 & .50 & ted & .07 & .25 & of-rights & .01 & .04 & .03 & .18 & 1.35 \\
\hline BIT & bite & .17 & .37 & little & .06 & .19 & horse & .11 & .13 & .17 & .13 & 2.07 \\
\hline BITTER & sweet & .34 & .65 & $\operatorname{mad}$ & .02 & .19 & & & & & .16 & .76 \\
\hline BLOCK & wood & .07 & .45 & stop & .03 & .22 & parent & .06 & .15 & & .18 & 1.43 \\
\hline BLOW & wind & .16 & .49 & job & .11 & .11 & hit & .04 & .08 & .07 & .25 & 1.45 \\
\hline BLUE & red & .18 & .85 & sad & .02 & .03 & movie & .01 & .01 & & .10 & .32 \\
\hline BLUFF & lie & .16 & .72 & cliff & .03 & .06 & grass & .02 & .04 & & .18 & .67 \\
\hline BLUNT & sharp & .21 & .76 & forward & .01 & .09 & & & & & .14 & .50 \\
\hline BOARD & game & .15 & .70 & meeting & .03 & .07 & ship & .03 & .06 & .01 & .17 & .85 \\
\hline BOIL & water & .45 & .89 & sore & .01 & .05 & & & & & .06 & .29 \\
\hline BOLT & nut & .18 & .46 & lightning & .22 & .24 & run & .10 & .19 & .01 & .09 & 1.55 \\
\hline BOND & glue & .10 & .30 & james & .27 & .28 & money & .14 & .23 & & .19 & 1.58 \\
\hline BOOM & bang & .16 & .74 & bust & .05 & .10 & camera & .01 & .01 & & .14 & .63 \\
\hline BOOT & shoe & .24 & .59 & kick & .09 & .11 & camp & .05 & .06 & .01 & .23 & 1.04 \\
\hline BOUND & tied & .15 & .61 & jump & .05 & .12 & homeward & .01 & .06 & & .22 & .96 \\
\hline Bow & arrow & .30 & .35 & tie & .19 & .26 & curtsey & .03 & .09 & .13 & .18 & 1.97 \\
\hline BOWL & cereal & .11 & .64 & ball & .05 & .24 & over & .02 & .02 & & .10 & .96 \\
\hline Box & square & .12 & .75 & tyson & .01 & .03 & pussy & .01 & .02 & & .20 & .38 \\
\hline BREAK & glass & .14 & .70 & time & .02 & .08 & through & .02 & .06 & & .17 & .79 \\
\hline BRIDGE & water & .21 & .60 & cards & .09 & .20 & deck & .01 & .01 & .01 & .18 & .98 \\
\hline BROKE & fix & .14 & .69 & money & .10 & .19 & & & & & .12 & .75 \\
\hline BRUSH & hair & .42 & .92 & fire & .02 & .03 & & & & & .06 & .18 \\
\hline BUG & insect & .10 & .74 & off & .04 & .07 & computer & .00 & .00 & & .19 & .48 \\
\hline BULB & light & .76 & .86 & flower & .05 & .11 & & & & & .03 & .52 \\
\hline CABINET & wood & .13 & .79 & minister & .05 & .12 & & & & & .08 & .57 \\
\hline CABLE & tv & .68 & .93 & knit & .01 & .01 & & & & & .07 & .05 \\
\hline CALF & cow & .65 & .81 & leg & .08 & .11 & & & & & .08 & .53 \\
\hline CALL & phone & .38 & .75 & yell & .05 & .12 & & & & & .13 & .59 \\
\hline CAN & soup & .11 & .67 & can't & .04 & .16 & washroom & .01 & .03 & .01 & .12 & 1.00 \\
\hline CANE & candy & .19 & .69 & sugar & .10 & .10 & & & & & .21 & .54 \\
\hline CAP & hat & .45 & .79 & pen & .02 & .06 & gun & .01 & .01 & & .14 & .43 \\
\hline CAPE & superman & .16 & .52 & $\operatorname{cod}$ & .23 & .41 & & & & & .07 & .99 \\
\hline CAPITAL & city & .35 & .60 & money & .06 & .16 & letter & .07 & .09 & .09 & .06 & 1.49 \\
\hline CARD & birthday & .20 & .47 & game & .10 & .42 & comedian & .01 & .01 & & .10 & 1.08 \\
\hline CARP & fish & .70 & .73 & & & & & & & & .27 & .00 \\
\hline CASE & lawyer & .07 & .47 & brief & .10 & .38 & & & & & .15 & .99 \\
\hline CAST & broken & .12 & .34 & play & .11 & .27 & away & .05 & .24 & .11 & .04 & 1.90 \\
\hline CELL & jail & .19 & .48 & biology & .14 & .40 & & & & & .12 & .99 \\
\hline CHAIN & link & .15 & .78 & letter & .03 & .10 & & & & & .12 & .52 \\
\hline CHANCE & luck & .22 & .54 & opportunity & .04 & .24 & & & & & .21 & .89 \\
\hline CHANGE & clothes & .14 & .49 & money & .25 & .41 & & & & & .10 & .99 \\
\hline CHARGE & card & .27 & .66 & bull & .05 & .12 & arrest & .02 & .07 & .06 & .09 & 1.27 \\
\hline CHARM & bracelet & .23 & .46 & wit & .03 & .39 & & & & & .15 & 1.00 \\
\hline CHECK & mark & .11 & .52 & money & .14 & .31 & mate & .07 & .07 & .02 & .08 & 1.38 \\
\hline CHEST & hair & .12 & .51 & treasure & .05 & .27 & & & & & .22 & .93 \\
\hline CHEW & gum & .35 & .91 & out & .01 & .01 & & & & & .08 & .09 \\
\hline CHINA & dishes & .09 & .51 & japan & .08 & .36 & & & & & .13 & .98 \\
\hline CHIP & potato & .13 & .68 & break & .03 & .11 & dale & .09 & .10 & & .11 & 1.02 \\
\hline CHOP & cut & .09 & .52 & suey & .21 & .35 & hit & .01 & .03 & & .10 & 1.15 \\
\hline CHUCK & throw & .17 & .26 & wagon & .14 & .25 & berry & .03 & .18 & .13 & .18 & 2.08 \\
\hline CLIP & board & .30 & .70 & cut & .07 & .15 & hit & .02 & .02 & .04 & .10 & 1.07 \\
\hline CLOG & drain & .35 & .74 & shoe & .11 & .18 & & & & & .08 & .72 \\
\hline CLUB & group & .07 & .45 & bat & .05 & .23 & night & .04 & .17 & .05 & .11 & 1.68 \\
\hline
\end{tabular}


Homograph Association Norms (Continued)

\begin{tabular}{|c|c|c|c|c|c|c|c|c|c|c|c|c|}
\hline Homograph & Primary 1 & P1 & M1 & Primary 2 & $\mathrm{P} 2$ & M2 & Primary 3 & $\mathrm{P} 3$ & M3 & $R$ & $X$ & 8 \\
\hline COAST & ocean & .13 & .77 & soap & .10 & .10 & glide & .02 & .07 & & .07 & .84 \\
\hline $\operatorname{COAT}$ & jacket & .23 & .89 & paint & .03 & .05 & & & & & .06 & .31 \\
\hline COLD & hot & .32 & .77 & sick & .03 & .10 & war & .02 & .03 & & .10 & .70 \\
\hline COMB & hair & .68 & .98 & rooster & .01 & .01 & & & & & .01 & .09 \\
\hline СОМРАCT & disc & .36 & .36 & small & .16 & .19 & makeup & .10 & .18 & .22 & .04 & 2.11 \\
\hline COMPANY & business & .08 & .53 & friends & .07 & .31 & & & & & .16 & .95 \\
\hline COMPOUND & fracture & .13 & .40 & $w$ & .09 & .26 & interest & .10 & .13 & .10 & .12 & 1.80 \\
\hline CONSOLE & help & .12 & .60 & car & .07 & .27 & & & & & .13 & .90 \\
\hline CONTACT & lens & .32 & .55 & touch & .07 & .15 & call & .02 & .10 & .01 & .19 & 1.25 \\
\hline CONTRACT & agreement & .07 & .74 & disease & .05 & .08 & dilate & .01 & .03 & & .16 & .64 \\
\hline COPY & cheat & .22 & .48 & machine & .09 & .42 & & & & & .10 & 1.00 \\
\hline CORD & rope & .17 & .82 & pants & .04 & .05 & wood & .01 & .01 & & .13 & .35 \\
\hline CORN & cob & .35 & .94 & feet & .01 & .01 & & & & & .05 & .09 \\
\hline COUNT & numbers & .26 & .71 & dracula & .16 & .21 & on & .02 & .02 & & .07 & .88 \\
\hline COUNTER & top & .24 & .53 & balance & .04 & .23 & numbers & .03 & .10 & & .14 & 1.30 \\
\hline COURSE & school & .13 & .70 & golf & .09 & .09 & path & .01 & .07 & .00 & .13 & .92 \\
\hline COURT & judge & .11 & .50 & tennis & .20 & .34 & date & .04 & .12 & & .05 & 1.39 \\
\hline COVERED & blanket & .08 & .73 & safe & .02 & .03 & & & & & .24 & .21 \\
\hline CRAB & lobster & .15 & .80 & animal & .03 & .09 & apple & .05 & .05 & .01 & .04 & .81 \\
\hline CRAFT & art & .13 & .69 & boat & .04 & .12 & crafty & .00 & .01 & & .17 & .73 \\
\hline CRANE & lift & .10 & .44 & bird & .27 & .33 & neck & .05 & .05 & & .19 & 1.25 \\
\hline CRANK & shaft & .22 & .75 & call & .05 & .15 & & & & & .11 & .65 \\
\hline CREST & toothpaste & .45 & .52 & badge & .04 & .23 & hill & .06 & .13 & .01 & .10 & 1.44 \\
\hline CRICKET & bug & .12 & .54 & game & .15 & .37 & & & & & .09 & .98 \\
\hline CROOK & thief & .24 & .77 & arm & .02 & .14 & & & & & .09 & .61 \\
\hline CRUST & bread & .38 & .90 & earth & .02 & .05 & & & & & .05 & .31 \\
\hline CUE & pool & .42 & .67 & card & .03 & .26 & & & & & .06 & .86 \\
\hline CUFF & shirt & .24 & .78 & hit & .10 & .18 & & & & & .05 & .69 \\
\hline CURB & car & .14 & .83 & appetite & .02 & .07 & & & & & .09 & .41 \\
\hline CYCLE & bike & .52 & .86 & circle & .03 & .08 & & & & & .06 & .42 \\
\hline DART & board & .36 & .77 & run & .02 & .06 & car & .03 & .03 & & .13 & .62 \\
\hline DASH & run & .38 & .61 & board & .10 & .14 & salt & .04 & .09 & .05 & .10 & 1.41 \\
\hline DATE & girl & .08 & .43 & time & .10 & .40 & fruit & .02 & .04 & & .13 & 1.23 \\
\hline DECK & boat & .08 & .63 & cards & .17 & .19 & hit & .05 & .08 & .03 & .07 & 1.30 \\
\hline DEED & good & .17 & .61 & will & .08 & .28 & & & & & .10 & .90 \\
\hline DEEP & water & .19 & .89 & heavy & .01 & .03 & & & & & .08 & .19 \\
\hline DEPOSIT & money & .48 & .94 & clean & .01 & .03 & & & & & .03 & .18 \\
\hline DESERT & storm & .17 & .68 & leave & .02 & .02 & & & & & .30 & .19 \\
\hline DIAMOND & ring & .47 & .89 & baseball & .03 & .04 & ace & .01 & .01 & & .06 & .32 \\
\hline DIE & live & .24 & .87 & dice & .01 & .02 & & & & & .12 & .13 \\
\hline DIGEST & food & .25 & .61 & reader's & .26 & .37 & & & & & .02 & .96 \\
\hline DIGIT & number & .45 & .70 & finger & .22 & .25 & & & & & .05 & .83 \\
\hline DIP & chip & .17 & .72 & stick & .09 & .13 & down & .02 & .05 & & .10 & .89 \\
\hline DIRT & mud & .19 & .89 & smut & .02 & .03 & & & & & .08 & .18 \\
\hline DIVE & water & .23 & .94 & my-house & .01 & .01 & & & & & .05 & .05 \\
\hline DOUGH & bread & .49 & .88 & money & .07 & .09 & & & & & .03 & .43 \\
\hline DOVE & bird & .31 & .77 & soap & .09 & .09 & in & .02 & .08 & & .06 & .86 \\
\hline DOWN & up & .53 & .88 & feather & .01 & .04 & syndrome & .02 & .02 & .02 & .04 & .53 \\
\hline DRAFT & beer & .30 & .30 & army & .12 & .28 & draw & .03 & .17 & .17 & .07 & 2.01 \\
\hline DRAG & race & .27 & .36 & pull & .13 & .34 & smoke & .04 & .07 & .10 & .13 & 1.82 \\
\hline DRAW & picture & .21 & .79 & gun & .03 & .10 & near & .01 & .01 & .01 & .10 & .63 \\
\hline DRESS & clothes & .11 & .88 & & & & & & & & .12 & .00 \\
\hline DRILL & bit & .13 & .59 & sergeant & .08 & .26 & & & & & .15 & .89 \\
\hline DRIP & water & .22 & .90 & loser & .02 & .04 & & & & & .06 & .26 \\
\hline DRIVE & car & .53 & .89 & golf & .01 & .02 & & & & & .09 & .13 \\
\hline DROP & fall & .11 & .78 & water & .03 & .14 & & & & & .09 & .61 \\
\hline DROVE & car & .41 & .80 & care & .01 & .05 & golf & .02 & .02 & & .14 & .44 \\
\hline DRUM & beat & .20 & .92 & up & .01 & .01 & & & & & .07 & .05 \\
\hline DRY & wet & .44 & .78 & beer & .07 & .18 & & & & & .04 & .70 \\
\hline DUCK & quack & .15 & .81 & under & .01 & .06 & & & & & .13 & .35 \\
\hline DUMP & garbage & .36 & .85 & break-up & .01 & .04 & & & & & .11 & .27 \\
\hline EAR & hear & .16 & .95 & & & & & & & & .05 & .00 \\
\hline ENTRANCE & exit & .62 & .96 & awed & .01 & .01 & & & & & .03 & .09 \\
\hline EXCISE & $\operatorname{tax}$ & .12 & .13 & remove & .02 & .09 & & & & & .78 & .98 \\
\hline EXPRESS & train & .17 & .58 & yourself & .08 & .30 & & & & & .12 & .92 \\
\hline FAIR & game & .06 & .44 & rides & .03 & .17 & dark & .03 & .15 & .11 & .14 & 1.89 \\
\hline FALL & down & .19 & .55 & autumn & .08 & .36 & & & & & .09 & .97 \\
\hline FAN & cool & .21 & .75 & club & .05 & .19 & & & & & .07 & .72 \\
\hline FANCY & dress & .16 & .77 & free & .04 & .09 & & & & & .15 & .48 \\
\hline
\end{tabular}


Homograph Association Norms (Continued)

\begin{tabular}{|c|c|c|c|c|c|c|c|c|c|c|c|c|}
\hline Homograph & Primary 1 & $\mathbf{P l}$ & M! & Primary 2 & $\mathrm{P} 2$ & M2 & Primary 3 & P3 & M3 & $R$ & $X$ & $U$ \\
\hline FARE & bus & .30 & .75 & well & .02 & .02 & & & & & .22 & .18 \\
\hline FAST & slow & .47 & .89 & eat & .02 & .03 & & & & & .09 & .19 \\
\hline FAULT & blame & .09 & .39 & earthquake & .06 & .19 & tennis & .04 & .08 & & .34 & 1.33 \\
\hline FAWN & deer & .59 & .78 & & & & & & & & .22 & .00 \\
\hline FELT & pen & .19 & .56 & touch & .06 & .30 & & & & & .14 & .93 \\
\hline FENCE & post & .13 & .83 & sword & .05 & .10 & crime & .01 & .01 & & .06 & .58 \\
\hline FIELD & dreams & .10 & .98 & & & & & & & & .02 & .00 \\
\hline FIGURE & skate & .14 & .70 & eight & .09 & .16 & out & .05 & .05 & & .09 & .95 \\
\hline FILE & cabinet & .20 & .72 & nail & .08 & .19 & rank & .01 & .01 & & .07 & .82 \\
\hline FILM & movie & .30 & .90 & black & .01 & .02 & • & & & & .08 & .12 \\
\hline FINE & money & .07 & .23 & line & .05 & .22 & tune & .04 & .21 & .08 & .26 & 1.91 \\
\hline FINISH & start & .27 & .91 & coat & .01 & .03 & & & & & .06 & .18 \\
\hline FIRE & hot & .16 & .87 & gun & .02 & .03 & hire & .01 & .01 & & .10 & .23 \\
\hline FIRM & hard & .13 & .82 & company & .04 & .14 & & & & & .04 & .61 \\
\hline FIT & shape & .06 & .40 & clothes & .08 & .36 & anger & .02 & .06 & & .18 & 1.29 \\
\hline FIX & break & .16 & .76 & $\operatorname{dog}$ & .01 & .02 & drink & .01 & .01 & .01 & .21 & .33 \\
\hline FLAT & round & .11 & .83 & apartment & .02 & .04 & beer & .02 & .04 & .02 & .08 & .62 \\
\hline FLEET & ships & .30 & .78 & run & .02 & .07 & & & & & .15 & .41 \\
\hline FLIGHT & plane & .36 & .85 & fancy & .01 & .03 & stairs & .02 & .02 & & .10 & .39 \\
\hline FLING & throw & .28 & .52 & affair & .13 & .26 & & & & & .22 & .92 \\
\hline FLOAT & boat & .18 & .79 & ice-cream & .04 & .12 & parade & .02 & .02 & .01 & .06 & .74 \\
\hline FLUSH & toilet & .77 & .81 & red & .06 & .09 & cards & .02 & .05 & .01 & .04 & .82 \\
\hline FLY & bird & .11 & .48 & bug & .11 & .34 & rod & .01 & .02 & .01 & .15 & 1.20 \\
\hline FOIL & $\operatorname{tin}$ & .28 & .76 & fool & .02 & .10 & fencing & .02 & .05 & .01 & .08 & .87 \\
\hline FOLD & paper & .23 & .88 & sheep & .01 & .01 & & & & & .11 & .09 \\
\hline FOOT & ball & .20 & .93 & long & .02 & .02 & & & & & .05 & .15 \\
\hline FORCE & push & .10 & .59 & air & .12 & .27 & & & & & .14 & .89 \\
\hline FORM & paper & .08 & .39 & shape & .08 & .29 & make & .06 & .14 & & .19 & 1.48 \\
\hline FOUL & smell & .17 & .46 & ball & .09 & .31 & & & & & .23 & .97 \\
\hline FRAME & picture & .63 & .93 & clue & .01 & .02 & & & & & .05 & .12 \\
\hline FRAY & jeans & .10 & .75 & fight & .04 & .07 & & & & & .18 & .44 \\
\hline FREE & jail & .04 & .50 & money & .06 & .34 & & & & & .16 & .97 \\
\hline FRESH & fruit & .15 & .90 & prince & .05 & .06 & people & .01 & .01 & & .04 & .37 \\
\hline FRISK & police & .23 & .66 & cat & .08 & .17 & & & & & .17 & .74 \\
\hline FRONT & back & .70 & .90 & line & .05 & .06 & & & & & .04 & .32 \\
\hline FUSE & box & .22 & .48 & light & .11 & .22 & together & .06 & .13 & & .17 & 1.38 \\
\hline GAG & choke & .20 & .49 & joke & .16 & .27 & mouth & .03 & .15 & & .09 & 1.43 \\
\hline GAME & play & .22 & .89 & animal & .01 & .03 & & & & & .08 & .19 \\
\hline GAS & car & .35 & .80 & fart & .03 & .03 & fun & .01 & .01 & & .16 & .28 \\
\hline GEAR & shift & .18 & .55 & camping & .05 & .31 & & & & & .13 & .94 \\
\hline GERM & disease & .17 & .87 & layer & .01 & .02 & & & & & .11 & .13 \\
\hline GIN & tonic & .37 & .87 & rummy & .07 & .08 & & & & & .05 & .42 \\
\hline GLARE & sun & .13 & .48 & stare & .25 & .47 & & & & & .05 & 1.00 \\
\hline GLASS & window & .10 & .63 & cup & .07 & .29 & & & & & .07 & .90 \\
\hline GRACE & prayer & .09 & .47 & ballet & .02 & .22 & kelly & .10 & .21 & & .10 & 1.48 \\
\hline GRADE & mark & .12 & .88 & steep & .02 & .04 & & & & & .08 & .26 \\
\hline GRAFT & skin & .46 & .52 & tree & .03 & .05 & con & .01 & .03 & & .40 & .68 \\
\hline GRAIN & wheat & .32 & .77 & sand & .11 & .17 & & & & & .06 & .68 \\
\hline GRASS & green & .51 & .82 & smoke & .05 & .07 & & & & & .11 & .41 \\
\hline GRATE & cheese & .62 & .74 & sewer & .03 & .15 & annoy & .01 & .02 & & .10 & .76 \\
\hline GRAVE & dead & .27 & .88 & mistake & .01 & .04 & & & & & .08 & .27 \\
\hline GREEN & grass & .18 & .94 & golf & .02 & .02 & & & & & .05 & .12 \\
\hline GRILL & barbecue & .21 & .94 & hound & .01 & .02 & & & & & .04 & .12 \\
\hline GRIND & coffee & .17 & .80 & work & .02 & .04 & & & & & .16 & .26 \\
\hline GROSS & disgusting & .10 & .49 & anatomy & .11 & .25 & big & .04 & .14 & .01 & .11 & 1.48 \\
\hline GROUND & dirt & .12 & .76 & beef & .12 & .17 & & & & & .07 & .69 \\
\hline GUY & girl & .41 & .64 & lafleur & .05 & .12 & wire & .01 & .01 & & .24 & .67 \\
\hline HABIT & bad & .19 & .79 & nun & .04 & .06 & & & & & .15 & .38 \\
\hline HAIL & rain & .25 & .68 & mary & .10 & .24 & & & & & .08 & .83 \\
\hline HAM & pig & .11 & .88 & funny & .01 & .03 & & & & & .09 & .21 \\
\hline HAMPER & clothes & .56 & .84 & stop & .03 & .10 & & & & & .06 & .49 \\
\hline HAND & foot & .19 & .93 & friendship & .01 & .01 & & & & & .06 & .09 \\
\hline HANG & $\operatorname{man}$ & .08 & .63 & loose & .05 & .09 & & & & & .28 & .54 \\
\hline HARD & soft & .38 & .75 & easy & .05 & .14 & & & & & .10 & .63 \\
\hline HARP & music & .31 & .80 & nag & .03 & .08 & & & & & .12 & .44 \\
\hline HATCH & egg & .27 & .44 & back & .15 & .43 & & & & & .13 & 1.00 \\
\hline HAUNT & ghost & .35 & .94 & & & & & & & & .06 & .00 \\
\hline HEAD & hair & .12 & .79 & start & .01 & .03 & & & & & .18 & .23 \\
\hline HEAT & cold & .27 & .95 & $\operatorname{dog}$ & .02 & .02 & & & & & .03 & .15 \\
\hline
\end{tabular}


Homograph Association Norms (Continued)

\begin{tabular}{|c|c|c|c|c|c|c|c|c|c|c|c|c|}
\hline Homograph & Primary 1 & P1 & M1 & Primary 2 & P2 & M2 & Primary 3 & P3 & M3 & $R$ & $X$ & $U$ \\
\hline HEEL & shoe & .25 & .86 & $\operatorname{dog}$ & .04 & .06 & & & & & .08 & .35 \\
\hline HEM & dress & .23 & .94 & & & & & & & & .06 & .00 \\
\hline HIDE & seek & .51 & .84 & animal & .01 & .07 & & & & & .09 & .39 \\
\hline HOLD & on & .15 & .91 & & & & & & & & .09 & .00 \\
\hline HOOD & car & .25 & .36 & robin & .28 & .31 & jacket & .10 & .23 & & .10 & 1.56 \\
\hline HOP & jump & .26 & .84 & hip & .05 & .09 & beer & .01 & .01 & & .07 & .50 \\
\hline HORN & car & .19 & .77 & cow & .04 & .17 & & & & & .06 & .67 \\
\hline HOST & hostess & .21 & .77 & parasite & .04 & .06 & bread & .02 & .04 & & .13 & .63 \\
\hline HOUND & $\operatorname{dog}$ & .87 & .91 & bother & .02 & .05 & & & & & .03 & .31 \\
\hline HULL & boat & .22 & .42 & brett & .13 & .36 & com & .02 & .05 & & .17 & 1.27 \\
\hline HUSKY & $\operatorname{dog}$ & .46 & .48 & big & .08 & .35 & gas & .07 & .15 & & .02 & 1.46 \\
\hline INCENSE & smell & .32 & .79 & anger & .02 & .06 & & & & & .15 & .36 \\
\hline INCLINE & decline & .19 & .92 & do & .01 & .05 & & & & & .03 & .30 \\
\hline INTEREST & hobby & .05 & .48 & money & .18 & .38 & & & & & .14 & .99 \\
\hline INTIMATE & close & .21 & .92 & suggest & .01 & .01 & & & & & .08 & .05 \\
\hline INVALID & wrong & .10 & .54 & sick & .07 & .27 & & & & & .20 & .92 \\
\hline IRON & fist & .05 & .49 & clothes & .17 & .47 & & & & & .04 & 1.00 \\
\hline ISSUE & magazine & .22 & .38 & debate & .06 & .30 & give & .05 & .16 & & .15 & 1.51 \\
\hline JACK & jill & .32 & .67 & hammer & .08 & .19 & queen & .04 & .08 & & .07 & 1.11 \\
\hline JAM & toast & .20 & .87 & stuck & .01 & .04 & session & .01 & .02 & & .07 & .40 \\
\hline JAR & jam & .40 & .93 & hit & .01 & .02 & & & & & .05 & .12 \\
\hline JERK & asshole & .09 & .59 & off & .11 & .32 & & & & & .09 & .93 \\
\hline JET & plane & .45 & .87 & ski & .04 & .08 & & & & & .05 & .42 \\
\hline JOINT & knee & .14 & .58 & smoke & .07 & .20 & together & .04 & .13 & .02 & .07 & 1.43 \\
\hline JUICE & orange & .55 & .95 & & & & & & & $'$ & .05 & .00 \\
\hline JUNK & garbage & .19 & .94 & boat & .01 & .01 & & & & & .05 & .09 \\
\hline KERNEL & corn & .46 & .89 & & & & & & & & .11 & .00 \\
\hline KEY & lock & .30 & .90 & word & .01 & .04 & board & .01 & .01 & & .05 & .35 \\
\hline KICK & ball & .19 & .96 & & & & & & & & .04 & .00 \\
\hline KID & child & .23 & .72 & goat & .10 & .10 & joke & .01 & .01 & & .16 & .64 \\
\hline KIND & nice & .25 & .91 & type & .02 & .04 & & & & & .04 & .26 \\
\hline LACE & dress & .08 & .67 & shoe & .12 & .26 & arsenic & .01 & .03 & & .04 & 1.03 \\
\hline LAND & water & .14 & .89 & plane & .02 & .07 & & & & & .04 & .37 \\
\hline LAP & sit & .17 & .54 & run & .03 & .13 & tongue & .03 & .08 & & .25 & 1.13 \\
\hline LASH & out & .21 & .69 & eye & .15 & .21 & tie & .01 & .01 & & .08 & .87 \\
\hline LEAD & pencil & .36 & .65 & follow & .18 & .33 & & & & & .03 & .92 \\
\hline LEAF & tree & .37 & .89 & page & .02 & .03 & through & .01 & .01 & & .08 & .24 \\
\hline LEAN & meat & .14 & .64 & over & .04 & .27 & & & & & .08 & .88 \\
\hline LEFT & right & .77 & .94 & behind & .02 & .04 & & & & & .03 & .23 \\
\hline LETTER & mail & .10 & .68 & alphabet & .03 & .07 & & & & & .25 & .46 \\
\hline LIE & truth & .21 & .65 & down & .15 & .25 & & & & & .10 & .85 \\
\hline LIGHT & dark & .30 & .78 & heavy & .06 & .10 & beer & .03 & .04 & .02 & .06 & .88 \\
\hline LIKE & hate & .22 & .74 & as & .03 & .10 & & & & & .16 & .52 \\
\hline LIME & lemon & .41 & .88 & light & .03 & .06 & & & & & .06 & .33 \\
\hline LIMP & leg . & .15 & .54 & wrist & .04 & .38 & & & & & .07 & .98 \\
\hline LINE & straight & .18 & .94 & & & & & & & & .06 & .00 \\
\hline LIP & kiss & .20 & .90 & sink & .02 & .03 & insolence & .01 & .01 & & .06 & .30 \\
\hline LIST & words & .09 & .83 & over & .01 & .03 & & & & & .14 & .22 \\
\hline LITTER & garbage & .23 & .56 & box & .15 & .15 & kittens & .04 & .11 & & .18 & 1.20 \\
\hline LOAF & bread & .82 & .91 & lazy & .03 & .06 & & & & & .04 & .32 \\
\hline LOBBY & hotel & .51 & .81 & government & .03 & .13 & & & & & .06 & .58 \\
\hline LOCK & key & .33 & .96 & barrel & .00 & .01 & hair & .00 & .00 & & .02 & .13 \\
\hline LOG & tree & .16 & .80 & book & .04 & .09 & logarithm & .01 & .04 & & .08 & .69 \\
\hline LOT & house & .14 & .66 & little & .06 & .17 & & & & & .16 & .74 \\
\hline LOUNGE & bar & .16 & .60 & chair & .11 & .37 & & & & & .03 & .96 \\
\hline LOW & high & .61 & .96 & & & & & & & & .04 & .00 \\
\hline MAD & angry & .26 & .52 & $\operatorname{dog}$ & .08 & .24 & magazine & .08 & .12 & & .12 & 1.36 \\
\hline MAJOR & minor & .42 & .64 & dad & .14 & .31 & & & & & .05 & .91 \\
\hline MARBLE & floor & .18 & .51 & game & .09 & .36 & & & & & .14 & .98 \\
\hline MARCH & april & .21 & .51 & walk & .09 & .47 & & & & & .02 & 1.00 \\
\hline MARK & grade & .07 & .42 & guy & .03 & .16 & pen & .02 & .14 & .03 & .25 & 1.58 \\
\hline MAROON & red & .17 & .56 & island & .12 & .28 & gullible & .01 & .01 & & .14 & 1.00 \\
\hline MASS & weight & .23 & .36 & media & .08 & .34 & church & .16 & .24 & & .06 & 1.56 \\
\hline MATCH & fire & .22 & .58 & maker & .03 & .17 & game & .06 & .16 & & .10 & 1.29 \\
\hline MEAL & food & .26 & .97 & corn & .01 & .01 & & & & & .02 & .09 \\
\hline MEAN & nice & .21 & .88 & average & .03 & .08 & it & .01 & .01 & & .03 & .49 \\
\hline MESS & room & .20 & .83 & hall & .06 & .09 & around & .02 & .02 & & .07 & .58 \\
\hline MIGHT & strong & .10 & .47 & maybe & .16 & .39 & & & & & .13 & .99 \\
\hline MIND & brain & .23 & .82 & manners & .01 & .04 & & & & & .14 & .25 \\
\hline
\end{tabular}


Homograph Association Norms (Continued)

\begin{tabular}{|c|c|c|c|c|c|c|c|c|c|c|c|c|}
\hline Homograph & Primary 1 & P1 & MI & Primary 2 & $\mathbf{P 2}$ & $\mathrm{M} 2$ & Primary 3 & P3 & M3 & $R$ & $X$ & $U$ \\
\hline MINE & yours & .49 & .58 & gold & .11 & .30 & field & .03 & .07 & & .04 & 1.25 \\
\hline MINT & candy & .25 & .85 & condition & .05 & .12 & & & & & .03 & .54 \\
\hline MINUTE & second & .28 & .87 & small & .04 & .06 & & & & & .07 & .34 \\
\hline MISS & america & .06 & .43 & hit & .09 & .42 & & & & & 15 & 1.00 \\
\hline MODEL & pretty & .10 & .56 & car & .10 & .39 & & & & & .05 & .98 \\
\hline MOLD & bread & .17 & .67 & clay & .05 & .27 & & & & & .06 & .86 \\
\hline MOLE & animal & .10 & .49 & face & .07 & .27 & chemistry & .04 & .08 & .01 & .15 & 1.42 \\
\hline MOTION & move & .13 & .84 & hand & .02 & .06 & lawyer & .01 & .01 & & .10 & .39 \\
\hline MUG & coffee & .37 & .84 & shot & .07 & .07 & anger & .01 & .05 & & .04 & .69 \\
\hline NAG & mom & .16 & .93 & horse & .04 & .04 & & & & & .03 & .26 \\
\hline NAIL & hammer & .41 & .58 & polish & .08 & .35 & & & & & .08 & .95 \\
\hline NAP & sleep & .67 & .95 & cloth & .01 & .01 & & & & & .04 & .05 \\
\hline NET & fish & .33 & .83 & gain & .04 & .14 & & & & & .03 & .60 \\
\hline NOTE & book & .17 & .84 & music & .07 & .10 & & & & & .06 & .48 \\
\hline NOVEL & book & .66 & .87 & idea & .06 & .09 & & & & & .04 & .45 \\
\hline NUT & cracker & .09 & .48 & case & .15 & .30 & bolt & .12 & .14 & & .08 & 1.43 \\
\hline OВJECT & thing & .19 & .65 & subject & .13 & .15 & agree & .02 & .10 & .04 & .07 & 1.32 \\
\hline ODD & weird & .14 & .51 & even & .39 & .46 & & & & & .03 & 1.00 \\
\hline OPERATION & doctor & .14 & .80 & desert-storm & .02 & .14 & & & & & .06 & .62 \\
\hline ORDER & food & .16 & .54 & chaos & .03 & .18 & command & .03 & .11 & & .17 & 1.27 \\
\hline ORGAN & heart & .16 & .50 & music & .15 & .47 & & & & & .03 & 1.00 \\
\hline PACK & back & .10 & .71 & wolves & .06 & .12 & cigarettes & .02 & .09 & & .07 & 1.01 \\
\hline PAD & paper & .34 & .54 & $\operatorname{maxi}$ & .04 & .21 & house & .04 & .12 & & .12 & 1.33 \\
\hline PAGE & book & .17 & .77 & boy & .03 & .13 & & & & & .10 & .60 \\
\hline PALM & hand & .42 & .59 & tree & .16 & .27 & & & & & .14 & .89 \\
\hline PANEL & wood & .13 & .51 & judges & .13 & .36 & & & & & .13 & .98 \\
\hline PARK & car & .25 & .45 & bench & .06 & .42 & & & & & .13 & 1.00 \\
\hline PART & time & .09 & .59 & hair & .15 & .30 & & & & & .11 & .92 \\
\hline PARTY & fun & .19 & .97 & line & .01 & .01 & & & & & .02 & .09 \\
\hline PASS & go & .06 & .43 & fail & .20 & .28 & bus & .04 & .16 & .01 & .12 & 1.52 \\
\hline PASSAGE & way & .13 & .89 & book & .02 & .08 & & & & & .03 & .42 \\
\hline PAT & $\operatorname{dog}$ & .09 & .65 & friend & .02 & .18 & butter & .01 & .02 & & .15 & .86 \\
\hline PATIENT & doctor & .36 & .79 & impatient & .03 & .13 & & & & & .08 & .59 \\
\hline PAWN & sell & .15 & .53 & chess & .29 & .39 & & & & & .07 & .98 \\
\hline PEER & friend & .31 & .69 & look & .12 & .21 & & & & & .10 & .78 \\
\hline PELT & beaver & .21 & .60 & rain & .08 & .33 & & & & & .07 & .94 \\
\hline PEN & pencil & .43 & .91 & pig & .02 & .04 & & & & & .05 & .24 \\
\hline PERCH & bird & .33 & .66 & fish & .30 & .32 & & & & & .02 & .91 \\
\hline PERFECT & excellent & .06 & .85 & & & & & & & & .15 & .00 \\
\hline PERIOD & time & .11 & .40 & sentence & .09 & .22 & blood & .05 & .20 & & .18 & 1.51 \\
\hline PERMIT & licence & .14 & .62 & allow & .23 & .34 & & & & & .04 & .93 \\
\hline PET & $\operatorname{dog}$ & .53 & .91 & fur & .01 & .02 & & & & & .07 & .12 \\
\hline PICK & up & .22 & .75 & axe & .04 & .14 & & & & & .11 & .62 \\
\hline PICKET & strike & .22 & .50 & fence & .44 & .45 & & & & & .05 & 1.00 \\
\hline PILE & shit & .13 & .90 & drive & .02 & .04 & carpet & .01 & .01 & & .05 & .34 \\
\hline PINCH & hurt & .20 & .80 & salt & .07 & .09 & hit & .02 & .03 & & .08 & .64 \\
\hline PIPE & smoke & .32 & .51 & line & .06 & .33 & organ & .03 & .08 & & .08 & 1.31 \\
\hline PIT & hole & .15 & .74 & cherry & .06 & .19 & & & & & .06 & .73 \\
\hline PITCH & baseball & .23 & .80 & sound & .02 & .06 & tent & .02 & .03 & .05 & .05 & .92 \\
\hline PITCHER & water & .16 & .49 & baseball & .24 & .48 & & & & & .04 & 1.00 \\
\hline PLAIN & simple & .11 & .81 & field & .02 & .10 & & & & & .09 & .50 \\
\hline PLANe & fly & .27 & .87 & flat & .02 & .07 & & & & & .06 & .39 \\
\hline PLANT & green & .27 & .93 & power & .02 & .02 & & & & & .05 & .15 \\
\hline PLAY & ball & .13 & .83 & shakespeare & .02 & .06 & music & .02 & .05 & & .05 & .66 \\
\hline PLOT & story & .21 & .48 & plan & .06 & .18 & graph & .10 & .17 & .12 & .04 & 1.78 \\
\hline POACH & egg & .37 & .59 & kill & .08 & .39 & & & & & .02 & .97 \\
\hline POINT & sharp & .11 & .40 & finger & .14 & .33 & break & .09 & .12 & .09 & .06 & 1.84 \\
\hline POKER & game & .23 & .87 & fire & .04 & .09 & & & & & .04 & .44 \\
\hline POLE & vault & .16 & .66 & north & .17 & .19 & polish & .01 & .01 & & .14 & .86 \\
\hline POOL & swim & .32 & .73 & table & .08 & .20 & car & .01 & .02 & & .05 & .89 \\
\hline PORT & boat & .15 & .66 & wine & .04 & .12 & bow & .02 & .09 & & .14 & 1.03 \\
\hline POST & office & .34 & .69 & fence & .04 & .14 & game & .01 & .07 & .03 & .07 & 1.17 \\
\hline POT & pan & .17 & .70 & drugs & .06 & .20 & & & & & .10 & .76 \\
\hline POUND & weight & .11 & .46 & hit & .06 & .25 & $\operatorname{dog}$ & .13 & .15 & .06 & .07 & 1.70 \\
\hline PRESENT & gift & .30 & .53 & past & .10 & .24 & show & .04 & .07 & .07 & .09 & 1.54 \\
\hline PRESS & down & .10 & .50 & news & .06 & .28 & iron & .12 & .20 & & .02 & 1.48 \\
\hline PRIME & time & .29 & .90 & number & .03 & .04 & paint & .03 & .04 & & .03 & .48 \\
\hline PRODUCE & vegetables & .14 & .70 & make & .10 & .26 & & & & & .04 & .85 \\
\hline PROJECT & work & .11 & .77 & voice & .02 & .11 & & & & & .12 & .55 \\
\hline
\end{tabular}


Homograph Association Norms (Continued)

\begin{tabular}{|c|c|c|c|c|c|c|c|c|c|c|c|c|}
\hline Homograph & Primary 1 & P1 & M1 & Primary 2 & $P 2$ & M2 & Primary 3 & $\mathrm{P} 3$ & M3 & $R$ & $X$ & $U$ \\
\hline PROOF & evidence & .17 & .70 & read & .10 & .14 & alcohol & .02 & .04 & .02 & .10 & 1.04 \\
\hline PRUNE & juice & .20 & .92 & cut & .02 & .03 & & & & & .05 & .21 \\
\hline PUMP & gas & .25 & .88 & & & & & & & & .12 & .00 \\
\hline PUNCH & hit & .17 & .70 & bowl & .07 & .23 & line & .03 & .03 & & .05 & .98 \\
\hline PUPIL & student & .49 & .67 & eye & .29 & .33 & & & & & .01 & .91 \\
\hline QUACK & duck & .69 & .71 & doctor & .14 & .23 & & & & & .06 & .80 \\
\hline QUEEN & king & .51 & .90 & fag & .01 & .01 & & & & & .09 & .09 \\
\hline QUIVER & shake & .45 & .76 & arrow & .07 & .18 & & & & & .06 & .71 \\
\hline RACE & run & .24 & .92 & color & .02 & .04 & & & & & .04 & .26 \\
\hline RACKET & ball & .47 & .80 & noise & .11 & .13 & mob & .02 & .03 & & .04 & .77 \\
\hline RAKE & leaves & .50 & .97 & & & & & & & & .03 & .00 \\
\hline RAM & goat & .12 & .59 & hit & .05 & .23 & computer & .02 & .03 & & .16 & 1.02 \\
\hline RANGE & domain & .10 & .36 & gun & .06 & .27 & stove & .11 & .17 & .06 & .14 & 1.77 \\
\hline RANK & army & .13 & .79 & smell & .05 & .12 & & & & & .09 & .57 \\
\hline RAP & music & .49 & .76 & knock & .03 & .09 & & & & & .15 & .47 \\
\hline RARE & unique & .04 & .46 & steak & .16 & .36 & & & & & .18 & .99 \\
\hline RASH & red & .26 & .85 & harsh & .02 & .06 & & & & & .09 & .35 \\
\hline REAR & end & .32 & .93 & horse & .02 & .03 & child & .01 & .01 & & .04 & .26 \\
\hline RECORD & music & .18 & .84 & break & .01 & .05 & write & .01 & .03 & & .08 & .51 \\
\hline REEL & fish & .30 & .78 & film & .05 & .11 & rock & .01 & .04 & .01 & .07 & .82 \\
\hline REFLECT & mirror & .28 & .59 & think & .15 & .34 & & & & & .08 & .95 \\
\hline REFRAIN & stop & .37 & .72 & song & .07 & .19 & & & & & .09 & .79 \\
\hline REFUSE & no & .24 & .72 & garbage & .14 & .19 & & & & & .09 & .75 \\
\hline REGISTER & school & .18 & .61 & cash & .20 & .33 & furnace & .01 & .02 & & .04 & 1.04 \\
\hline RELISH & mustard & .32 & .91 & love & .02 & .07 & & & & & .02 & .38 \\
\hline RENT & apartment & .15 & .97 & & & & & & & & .03 & .00 \\
\hline RESERVATION & hotel & .24 & .70 & indian & .12 & .19 & unsure & .01 & .02 & & .09 & .88 \\
\hline RESERVE & save & .07 & .45 & indian & .11 & .21 & army & .09 & .19 & .03 & .12 & 1.62 \\
\hline RESORT & holiday & .12 & .92 & last & .02 & .04 & & & & & .05 & .24 \\
\hline REST & sleep & .43 & .93 & all & .01 & .01 & & & & & .06 & .0 \\
\hline RIB & cage & .13 & .93 & bug & .01 & .02 & condoms & .01 & .01 & & .04 & .2 \\
\hline RICH & poor & .54 & .88 & little & .02 & .04 & chocolate & .01 & .02 & & .05 & .4 \\
\hline RIDDLE & joke & .38 & .92 & bullets & .01 & .01 & & & & & .08 & .05 \\
\hline RIGHT & left & .43 & .53 & wrong & .36 & .40 & now & .02 & .05 & .01 & .02 & 1.27 \\
\hline RING & finger & .14 & .63 & bell & .11 & .30 & & & & & .07 & .91 \\
\hline ROAD & car & .08 & .94 & & & & & & & & .06 & .00 \\
\hline ROCK & roll & .28 & .46 & stone & .08 & .26 & baby & .01 & .02 & & .26 & 1.10 \\
\hline ROLL & over & .09 & .60 & bread & .05 & .19 & rock & .13 & .13 & .02 & .06 & 1.38 \\
\hline ROOM & bed & .18 & .79 & space & .05 & .06 & & & & & .15 & .38 \\
\hline ROOT & tree & .31 & .75 & evil & .02 & .08 & dig & .02 & .02 & .01 & .14 & .6 \\
\hline ROSE & flower & .30 & .86 & axel & .01 & .03 & up & .01 & .02 & & .09 & .3 \\
\hline ROUND & square & .24 & .83 & robin & .02 & .06 & off & .02 & .03 & & .07 & .57 \\
\hline Row & boat & .55 & .66 & column & .09 & .27 & fight & .02 & .02 & & .06 & .98 \\
\hline RUBBER & band & .24 & .83 & condom & .12 & .15 & & & & & .02 & .61 \\
\hline RULER & measure & .19 & .75 & king & .10 & .18 & & & & & .07 & .70 \\
\hline RUNG & ladder & .42 & .46 & ring & .09 & .29 & out & .04 & .16 & & .09 & 1.47 \\
\hline RUNNER & fast & .06 & .66 & shoe & .09 & .21 & & & & & .13 & .79 \\
\hline SACK & potatoes & .26 & .78 & bed & .05 & .06 & quarterback & .02 & .04 & .02 & .10 & .8 \\
\hline SAGE & spice & .30 & .72 & wise & .04 & .12 & & & & & .16 & .5 \\
\hline SAP & tree & .68 & .84 & wimp & .02 & .06 & cry & .01 & .02 & & .08 & .4 \\
\hline SASH & belt & .18 & .74 & curtain & .03 & .04 & & & & & .23 & .27 \\
\hline SAW & cut & .15 & .66 & see & .18 & .30 & & & & & .04 & .90 \\
\hline SCALE & weight & .45 & .77 & fish & .03 & .05 & building & .01 & .05 & .06 & .06 & 1.02 \\
\hline SCALLOP & potatoes & .34 & .53 & fish & .16 & .35 & & & & & .11 & .97 \\
\hline SCHOOL & bus & .10 & .92 & & & & & & & & .08 & .00 \\
\hline SCOOP & ice-cream & .62 & .93 & news & .02 & .04 & neck & .02 & .02 & & .01 & .37 \\
\hline SCRAP & metal & .22 & .78 & fight & .13 & .14 & & & & & .08 & .61 \\
\hline SCRATCH & itch & .33 & .95 & game & .01 & .01 & & & & & .04 & .0 \\
\hline SCREEN & movie & .17 & .61 & door & .19 & .30 & pass & .01 & .01 & & .08 & .99 \\
\hline SCRUB & clean & .21 & .97 & bush & .02 & .02 & forget & .01 & .01 & & .01 & .19 \\
\hline SEAL & animal & .08 & .50 & close & .08 & .40 & & & & & .10 & .99 \\
\hline SEASON & fall & .25 & .97 & herb & .01 & .01 & & & & & .02 & .0 \\
\hline SECOND & first & .34 & .67 & minute & .06 & .08 & & & & & .24 & .5 \\
\hline SENSE & smell & .27 & .74 & common & .04 & .15 & & & & & .11 & .65 \\
\hline SENTENCE & structure & .17 & .72 & jail & .07 & .21 & & & & & .07 & .77 \\
\hline SET & up & .09 & .34 & jet & .02 & .16 & tv & .10 & .10 & .22 & .17 & 2.34 \\
\hline SHARE & give & .08 & .67 & money & .03 & .09 & & & & & .24 & .51 \\
\hline SHARP & knife & .19 & .78 & calculator & .08 & .11 & pain & .02 & .06 & .02 & .03 & .98 \\
\hline SHED & tools & .08 & .52 & hair & .10 & .40 & & & & & .08 & .9 \\
\hline
\end{tabular}


Homograph Association Norms (Continued)

\begin{tabular}{|c|c|c|c|c|c|c|c|c|c|c|c|c|}
\hline Homograph & Primary 1 & P1 & MI & Primary 2 & $\mathrm{P} 2$ & M2 & Primary 3 & P3 & M3 & $R$ & $X$ & $U$ \\
\hline SHELL & sea & .25 & .61 & gas & .10 & .22 & shock & .06 & .12 & & .06 & 1.27 \\
\hline SHIFT & gears & .15 & .71 & work & .15 & .22 & dress & .01 & .02 & & .06 & .90 \\
\hline SHIP & boat & .19 & .91 & across & .01 & .03 & & & & & .05 & .21 \\
\hline SHOOT & gun & .34 & .96 & camera & .01 & .02 & flower & .01 & .01 & & .02 & .20 \\
\hline SHOT & gun & .44 & .83 & glass & .03 & .05 & put & .04 & .04 & .01 & .07 & .60 \\
\hline SHOWER & clean & .14 & .65 & rain & .01 & .01 & bridal & .01 & .01 & & .33 & .23 \\
\hline SHUTTLE. & space & .35 & .90 & $\operatorname{cock}$ & .03 & .04 & & & & & .06 & .24 \\
\hline SIDE & door & .10 & .81 & friends & .01 & .03 & & & & & .16 & .20 \\
\hline SIGN & stop & .31 & .64 & up & .08 & .26 & & & & & .10 & .86 \\
\hline SINK & dishes & .11 & .56 & swim & .06 & .29 & & & & & .15 & .93 \\
\hline SKIRT & dress & .20 & .93 & around & .01 & .02 & & & & & .05 & .12 \\
\hline SLAB & meat & .32 & .95 & coffee & .01 & .01 & & & & & .05 & .05 \\
\hline SLIDE & down & .17 & .84 & show & .03 & .09 & & & & & .07 & .46 \\
\hline SLING & shot & .38 & .54 & arm & .19 & .37 & drink & .01 & .02 & & .07 & 1.11 \\
\hline SLIP & fall & .32 & .65 & dress & .07 & .22 & paper & .03 & .05 & & .08 & 1.09 \\
\hline SLUG & bug & .08 & .66 & hit & .08 & .14 & bub & .05 & .05 & .05 & .09 & 1.22 \\
\hline SMACK & hit & .33 & .58 & kiss & .14 & .29 & crack & .01 & .02 & & .11 & 1.03 \\
\hline SMART & dumb & .28 & .71 & alec & .05 & .07 & & & & & .22 & .43 \\
\hline SMELT & melt & .08 & .30 & nose & .04 & .24 & fish & .14 & .19 & & .26 & 1.56 \\
\hline SNAP & break & .12 & .72 & button & .06 & .09 & power & .02 & .05 & .05 & .08 & 1.12 \\
\hline SOCK & shoe & .34 & .88 & punch & .01 & .03 & & & & & .09 & .22 \\
\hline SOLE & shoe & .41 & .60 & fish & .17 & .22 & provider & .03 & .09 & & .09 & 1.22 \\
\hline SORE & pain & .10 & .72 & cold & .03 & .12 & loser & .03 & .04 & & .13 & .81 \\
\hline SOUND & music & .20 & .93 & advice & .00 & .01 & & & & & .06 & .08 \\
\hline sow & pig & .35 & .56 & seeds & .09 & .38 & & & & & .06 & .97 \\
\hline SPADE & shovel & .34 & .66 & cards & .09 & .27 & & & & & .08 & .87 \\
\hline SPARE & tire & .56 & .90 & bowling & .01 & .02 & life & .01 & .02 & & .06 & .32 \\
\hline SPEAKER & talk & .10 & .58 & loud & .14 & .31 & & & & & .11 & .93 \\
\hline SPEED & fast & .23 & .91 & drug & .03 & .05 & & & & & .04 & .29 \\
\hline SPELL & words & .11 & .72 & bound & .08 & .14 & & & & & .14 & .64 \\
\hline SPOT & stain & .10 & .45 & $\operatorname{dog}$ & .38 & .39 & see & .05 & .09 & .01 & .07 & 1.43 \\
\hline SPRAY & water & .17 & .99 & & & & & & & & .01 & .00 \\
\hline SPREAD & butter & .33 & .72 & eagle & .05 & .24 & & & & & .03 & .81 \\
\hline SPRING & summer & .15 & .57 & board & .04 & .15 & jump & .03 & .14 & .05 & .10 & 1.49 \\
\hline SQUARE & circle & .28 & .79 & root & .04 & .08 & head & .02 & .06 & .02 & .05 & .88 \\
\hline SQUASH & racquet & .13 & .58 & bug & .06 & .20 & vegetable & .06 & .18 & & .04 & 1.36 \\
\hline STABLE & horse & .41 & .65 & unstable & .05 & .26 & & & & & .09 & .87 \\
\hline STAFF & work & .10 & .80 & stick & .03 & .11 & & & & & .10 & .52 \\
\hline STAG & party & .41 & .70 & deer & .12 & .22 & & & & & .08 & .79 \\
\hline STAGE & play & .18 & .92 & coach & .03 & .03 & early & .01 & .01 & & .04 & .27 \\
\hline STAKE & vampire & .08 & .63 & claim & .05 & .11 & out & .08 & .09 & & .17 & 1.04 \\
\hline STALK & hunt & .09 & .63 & corn & .10 & .27 & & & & & .09 & .88 \\
\hline STALL & horse & .26 & .55 & car & .16 & .19 & wait & .07 & .13 & & .13 & 1.32 \\
\hline STAMP & letter & .31 & .74 & out & .03 & .13 & & & & & .12 & .61 \\
\hline STAND & sit & .33 & .89 & tv & .01 & .04 & & & & & .06 & .27 \\
\hline STAPLE & paper & .25 & .81 & food & .07 & .11 & & & & & .08 & .53 \\
\hline STAR & sky & .15 & .77 & movie & .03 & .12 & & & & & .11 & .57 \\
\hline STATE & province & .11 & .70 & mind & .03 & .07 & say & .02 & .06 & & .17 & .79 \\
\hline STATIC & cling & .34 & .82 & dynamic & .03 & .10 & & & & & .08 & .50 \\
\hline STEEP & hill & .45 & .93 & cook & .01 & .01 & & & & & .07 & .05 \\
\hline STEER & cow & .21 & .52 & drive & .11 & .42 & & & & & .06 & .99 \\
\hline STERN & mean & .15 & .72 & boat & .10 & .21 & & & & & .07 & .77 \\
\hline STEW & beef & .22 & .89 & & & & & & & & .11 & .00 \\
\hline STICK & gum & .14 & .73 & around & .01 & .06 & up & .03 & .05 & & .16 & .68 \\
\hline STILL & quiet & .09 & .77 & again & .02 & .09 & booze & .02 & .06 & & .08 & .82 \\
\hline STING & bee & .62 & .82 & music & .04 & .09 & police & .02 & .03 & & .07 & .63 \\
\hline STIR & fry & .20 & .91 & crazy & .02 & .04 & & & & & .06 & .23 \\
\hline STITCH & sew & .52 & .86 & cramp & .01 & .02 & & & & & .12 & .13 \\
\hline STOCK & market & .18 & .39 & car & .07 & .39 & cows & .05 & .12 & .03 & .08 & 1.58 \\
\hline STOLE & thief & .09 & .78 & fur & .07 & .13 & & & & & .09 & .60 \\
\hline STORE & buy & .09 & .50 & room & .07 & .26 & & & & & .23 & .93 \\
\hline STORY & book & .35 & .97 & two & .01 & .02 & & & & & .02 & .12 \\
\hline STRAIN & stress & .07 & .69 & noodles & .04 & .25 & culture & .01 & .03 & & .04 & .99 \\
\hline STRAND & hair & .58 & .80 & island & .04 & .13 & & & & & .07 & .58 \\
\hline STRAW & hat & .28 & .61 & drink & .12 & .31 & & & & & .08 & .92 \\
\hline STRAY & cat & .55 & .88 & away & .01 & .05 & & & & & .07 & .28 \\
\hline STRESS & school & .15 & .84 & this & .01 & .02 & & & & & .15 & .13 \\
\hline STRIKE & hit & .21 & .35 & out & .12 & .30 & workers & .04 & .25 & .02 & .08 & 1.69 \\
\hline STRIP & tease & .13 & .81 & paper & .03 & .12 & & & & & .07 & .55 \\
\hline
\end{tabular}


Homograph Association Norms (Continued)

\begin{tabular}{|c|c|c|c|c|c|c|c|c|c|c|c|c|}
\hline Homograph & Primary 1 & P1 & M1 & Primary 2 & $\mathrm{P} 2$ & M2 & Primary 3 & P3 & M3 & $R$ & $X$ & $U$ \\
\hline STROKE & swim & .11 & .61 & heart & .11 & .29 & & & & & .10 & .91 \\
\hline STUD & $\operatorname{man}$ & .16 & .71 & nail & .04 & .09 & earring & .03 & .06 & & .14 & .84 \\
\hline SUBJECT & math & .17 & .61 & object & .11 & .21 & to & .02 & .02 & .01 & .15 & 1.06 \\
\hline SUIT & tie & .21 & .83 & law & .01 & .02 & card & .01 & .02 & & .14 & .29 \\
\hline SWALLOW & food & .09 & .72 & bird & .21 & .24 & & & & & .04 & .81 \\
\hline SWAMP & thing & .11 & .93 & & & & & & & & .07 & .00 \\
\hline SWEAR & curse & .14 & .72 & oath & .05 & .12 & & & & & .16 & .59 \\
\hline SwITCH & light & .27 & .91 & stick & .01 & .03 & & & & & .07 & .18 \\
\hline TAB & bill & .13 & .40 & pop & .14 & .24 & book & .02 & .11 & .10 & .15 & 1.78 \\
\hline TACK & pin & .12 & .75 & horse & .03 & .07 & sail & .02 & .03 & & .15 & .64 \\
\hline TAG & $\operatorname{dog}$ & .05 & .44 & game & .16 & .43 & & & & & .12 & 1.00 \\
\hline TAP & dance & .22 & .51 & water & .25 & .38 & phone & .02 & .04 & & .08 & 1.19 \\
\hline TAPER & pants & .08 & .73 & & & & & & & & .27 & .00 \\
\hline TART & pie & .09 & .48 & sweet & .14 & .35 & slut & .03 & .07 & & .10 & 1.31 \\
\hline TAX & money & .21 & .84 & difficult & .01 & .01 & & & & & .16 & .05 \\
\hline TEAR & rip & .30 & .61 & cry & .12 & .32 & & & & & .07 & .93 \\
\hline TEMPLE & church & .16 & .62 & head & .18 & .31 & & & & & .08 & .92 \\
\hline TEND & help & .10 & .50 & tendency & .02 & .11 & & & & & .39 & .67 \\
\hline TENDER & soft & .13 & .89 & money & .06 & .09 & & & & & .02 & .45 \\
\hline TERM & paper & .30 & .73 & word & .07 & .15 & & & & & .12 & .65 \\
\hline TERMINAL & illness & .18 & .48 & bus & .16 & .40 & computer & .07 & .07 & & .05 & 1.29 \\
\hline TERMS & endearment & .13 & .43 & school & .10 & .23 & words & .07 & .16 & & .18 & 1.46 \\
\hline THROW & ball & .33 & .98 & & & & & & & & .02 & .00 \\
\hline TICK & bug & .13 & .47 & tock & .29 & .39 & off & .02 & .04 & & .09 & 1.22 \\
\hline TIE & suit & .10 & .51 & knot & .07 & .36 & game & .01 & .02 & & .12 & 1.09 \\
\hline TILL & money & .25 & .61 & tomorrow & .03 & .14 & soil & .03 & .13 & & .12 & 1.20 \\
\hline TIP & top & .17 & .46 & money & .12 & .29 & off & .05 & .10 & .10 & .06 & 1.70 \\
\hline TIRE & car & .25 & .87 & bored & .01 & .05 & & & & & .08 & .31 \\
\hline TOAST & jam & .33 & .88 & wine & .03 & .09 & & & & & .03 & .45 \\
\hline TOLL & booth & .27 & .92 & bell & .03 & .03 & effect & .01 & .01 & & .05 & .26 \\
\hline TOOL & hammer & .30 & .90 & fool & .01 & .02 & & & & & .08 & .16 \\
\hline TOP & bottom & .49 & .88 & spin & .04 & .04 & & & & & .08 & .26 \\
\hline TRACE & draw & .14 & .57 & find & .04 & .21 & element & .02 & .06 & & .16 & 1.16 \\
\hline TRACK & field & .31 & .81 & down & .02 & .09 & & & & & .10 & .47 \\
\hline TRADE & barter & .07 & .79 & mark & .06 & .14 & & & & & .07 & .61 \\
\hline TRAIN & track & .10 & .82 & learn & .02 & .07 & wedding & .01 & .01 & & .10 & .44 \\
\hline TREAT & candy & .24 & .76 & nice & .02 & .13 & & & & & .11 & .59 \\
\hline TRIAL & court & .24 & .59 & error & .18 & .31 & & & & & .09 & .93 \\
\hline TRIM & hair & .19 & .55 & slim & .06 & .19 & tree & .07 & .17 & & .09 & 1.35 \\
\hline TRIP & vacation & .11 & .65 & fall & .21 & .30 & & & & & .05 & .90 \\
\hline TRUNK & car & .39 & .66 & elephant & .13 & .13 & tree & .12 & .12 & & .09 & 1.12 \\
\hline TRUST & me & .13 & .70 & bank & .11 & .22 & & & & & .08 & .80 \\
\hline TRY & hard & .27 & .84 & jail & .01 & .01 & & & & & .15 & .05 \\
\hline TURN & around & .19 & .92 & change & .01 & .02 & & & & & .06 & .15 \\
\hline TYPE & writer & .12 & .63 & kind & .09 & .26 & & & & & .11 & .87 \\
\hline UPSET & $\operatorname{mad}$ & .16 & .82 & defeat & .01 & .07 & & & & & .11 & .41 \\
\hline VAIN & mirror & .15 & .59 & attempt & .01 & .05 & & & & & .36 & .38 \\
\hline VAULT & money & .38 & .76 & pole & .07 & .22 & & & & & .03 & .77 \\
\hline VENT & air & .38 & .77 & anger & .08 & .18 & & & & & .05 & .70 \\
\hline VESSEL & ship & .39 & .75 & blood & .08 & .11 & bottle & .01 & .06 & & .08 & .87 \\
\hline VICE & miami & .15 & .32 & president & .21 & .27 & grip & .14 & .22 & .11 & .08 & 1.90 \\
\hline VOLUME & loud & .22 & .61 & water & .03 & .21 & book & .07 & .12 & & .06 & 1.27 \\
\hline WAKE & sleep & .31 & .84 & boat & .02 & .06 & funeral & .02 & .05 & & .05 & .64 \\
\hline WALKER & baby & .18 & .58 & runner & .12 & .21 & sky & .02 & .08 & & .13 & 1.20 \\
\hline WASH & clean & .19 & .99 & & & & & & & & .01 & .00 \\
\hline WASTE & garbage & .35 & .94 & away & .01 & .01 & & & & & .05 & .09 \\
\hline WATCH & time & .40 & .66 & look & .06 & .30 & & & & & .03 & .90 \\
\hline WAVE & water & .22 & .71 & goodbye & .06 & .21 & & & & & .08 & .78 \\
\hline WAX & candle & .17 & .93 & wane & .01 & .01 & & & & & .06 & .05 \\
\hline WEAR & clothes & .43 & .73 & tear & .09 & .21 & & & & & .06 & .76 \\
\hline WELL & water & .41 & .57 & sick & .09 & .35 & & & & & .08 & .96 \\
\hline WILL & death & .16 & .41 & not & .12 & .27 & power & .05 & .16 & & .16 & 1.49 \\
\hline WIND & blow & .17 & .88 & up & .02 & .08 & & & & & .04 & .42 \\
\hline WING & bird & .43 & .93 & hit & .01 & .01 & & & & & .06 & .05 \\
\hline WORK & hard & .27 & .96 & & & & & & & & .04 & .00 \\
\hline
\end{tabular}


Homograph Association Norms (Continued)

\begin{tabular}{|c|c|c|c|c|c|c|c|c|c|c|c|c|}
\hline Homograph & Primary 1 & PI & MI & Primary 2 & $\mathbf{P} 2$ & M2 & Primary 3 & P3 & M3 & $R$ & $X$ & $U$ \\
\hline WOUND & hurt & .29 & .77 & up & .07 & .19 & & & & & .04 & .71 \\
\hline YARD & grass & .14 & .63 & stick & .15 & .29 & & & & & .08 & .90 \\
\hline YARN & wool & .24 & .88 & story & .02 & .04 & & & & & .08 & .24 \\
\hline YELLOW & green & .14 & .95 & coward & .02 & .03 & & & & & .02 & .20 \\
\hline YIELD & stop & .39 & .90 & crop & .01 & .07 & & & & & .03 & .37 \\
\hline YOKE & egg & .60 & .68 & ox & .07 & .27 & & & & & .05 & .86 \\
\hline ZEST & soap & .78 & .82 & life & .05 & .15 & lemon & .01 & .01 & & .02 & .70 \\
\hline
\end{tabular}

Note-Primary1, Primary2, Primary 3 = primary associate to the first, second, and third most frequent meanings. P1, P2, P3 = proportion of primary associate responses to the homograph for the first, second, and third most frequent meanings, respectively. M1, M2, M3 = proportion of responses to the homograph for the first, second, and third most frequent meanings, respectively. $R=$ proportion of responses to the homograph for all remaining meanings, if any. $X=$ proportion of Unclear responses (see text for description), $U$ = overall ambiguity of the homograph, in terms of uncertainty of information.

APPENDIX B

Polarized and Balanced Homographs

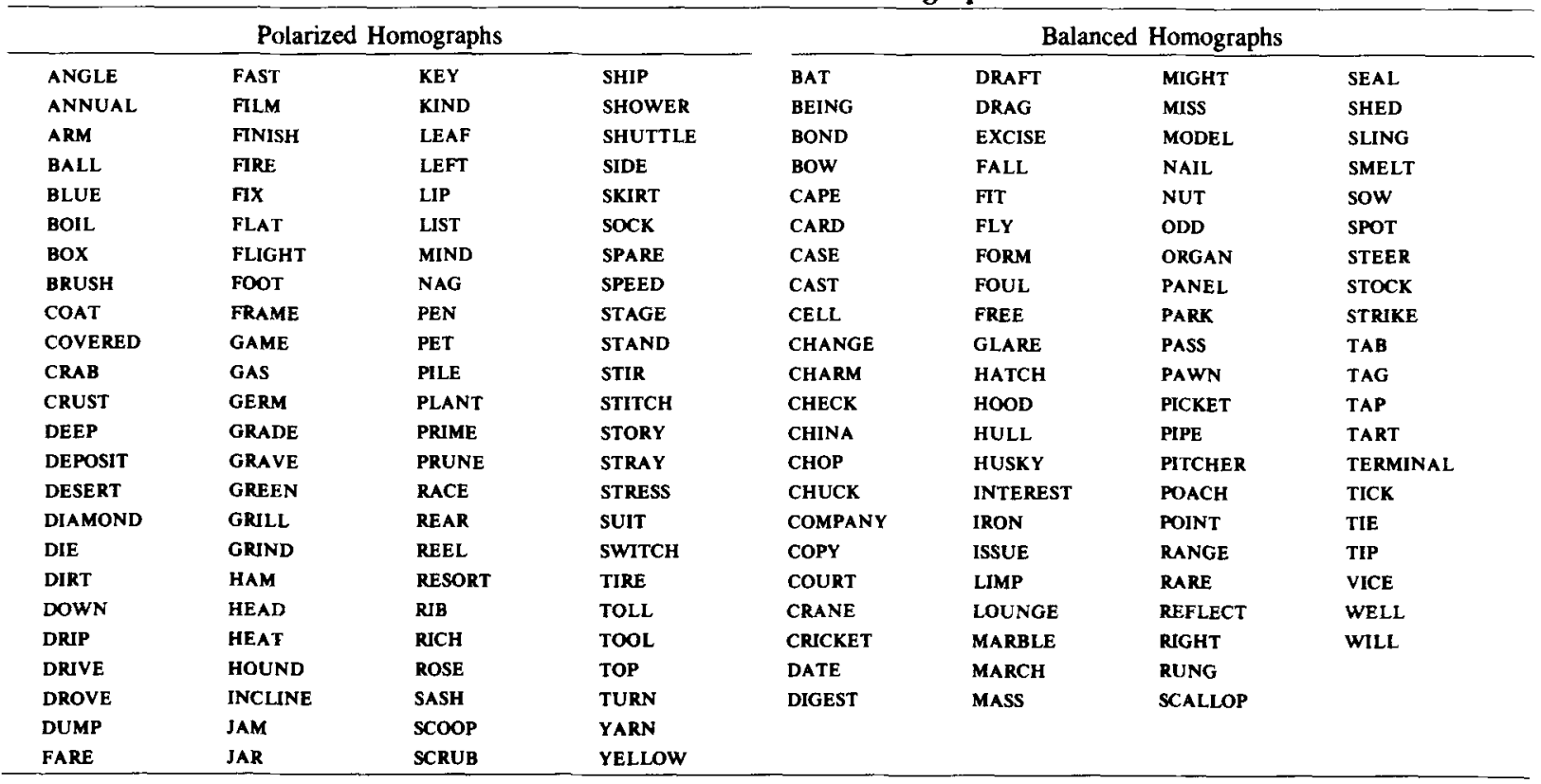

(Manuscript received April 29, 1992;

revision accepted for publication June 4, 1993.) 